\title{
A comprehensive review on the effect of plant metabolites on coronaviruses: focusing on their molecular docking score and IC50 values
}

Parastou Farshia, Eda Ceren Kayaa, Fataneh Hashempour-Baltorkb, Kianoush Khosravi-Daranic*

a Food Science Institute, Kansas State University, Manhattan, Kansas, USA

b Student Research Committee, Department of Food Science and Technology, National

Nutrition and Food Technology Research Institute, Faculty of Nutrition Science and Food Technology, Shahid Beheshti University of Medical Sciences, Tehran, Iran

c Department of Food Science and Technology, National Nutrition and Food Technology Research Institute, Faculty of Nutrition Science and Food Technology, Shahid Beheshti University of Medical Sciences, Tehran, Iran

Running title: The effect of plant metabolites on coronaviruses

\section{Correspondence}

Prof. Kianoush Khosravi-Darani, k.khosravi@sbmu.ac.ir,kiankh@yahoo.com,

Fax: 98-21-22376473

Tel: 98-21-22086348 


\begin{abstract}
Coronaviruses such as SARS (severe acute respiratory syndrome), MERS (Middle East respiratory syndrome), and newly emerged SARS-CoV-2, also called 2019-nCoV and COVID 19, have caused worldwide outbreaks in different time periods. There are many studies about chemical and natural drugs to treat these coronaviruses by inhibiting their proteases or their protein receptors through binding to amino acid residues. Plants secondary and primary metabolites are considered as potential drugs to inhibit various types of coronaviruses. IC50 value (the concentration in which there is $50 \%$ loss in enzyme activity) and molecular docking score and binding energy are parameters to understand the metabolites ability to inhibit the specific virus. In this study we did review on more than 110 papers on plant metabolites effect on different coronaviruses. Secondary plant metabolites such as polyphenols (flavonoids, coumarins, stilbenes), alkaloids, terpenoids, organosulfur compounds saponins, saikosaponins, lectins, essential oils, nicotianamine and primary metabolites such as vitamins.
\end{abstract}

Keywords: Coronaviruses, plants metabolites, polyphenols, antiviral-effect

Abbriviations: SARS: severe acute respiratory syndrome, MERS: Middle East respiratory syndrome, 3CLpro: chymotrypsin-like cysteine protease, PLpro: papain like protease, Mpro: main protease, HCoV: human coronavirus, SARS-CoV: SARS coronavirus, ACE2: angiotensin-converting enzyme 2, EGCG: epigallocatechin gallate, GCG: gallocatechin gallate, EGC: epigallocatechin, AMPLS: ampelopsin, TGEV: porcine transmissible gastroenteritis virus, PRCV: procine respiratory coronavirus, PEDV: porcine epidemic diarrhea virus, F1PV: feline infectious peritonitis virus, FCoV: feline coronavirus, canine coronavirus (CCOV, dog), rabbit coronavirus (RaCoV, rabbit), RCoV: rat coronavirus, SDAV: sialodacryoadenitis virus, BEV: bovine enteric virus, BCoV: bovine coronavirus, IBV: Avian infectious bronchitis virus, TCoV or TECoV: Turkey coronavirus or Transmissible gastroenteritis virus, MHV: murine hepatitis virus, nsPs: non-structural proteins, S protein: spike protein, TP: theophylline, TF1: theaflavin, TF2A: theaflavin-3 monogallate, TF2B: theaflavin-3' monogallate, and TF3: theaflavin-3,3' digallate, MolDock: moldocking, PLP2: Papain-Like Protease 2, HHA: hippeastrum hybrid (Amaryllis), GRFT: griffithsin, UDA: urtica dioica agglutinin, MLB: mannose binding lectin, EO: Essential oil, HCQ: Hydroxychloroquine, IC50: The half maximal inhibitory concentration, EC50: half maximal effective concentration. 


\section{Introduction}

Coronaviruses are considered as a family of RNA viruses that have helical nucleocapsids and extremely large genomes. Nucleotides in the coronavirus genomic RNA, determines the structural and nonstructural proteins of the virus. Some of the nonstructural proteins have pivotal role in viral RNA synthesis (replicase-transcriptase proteins), and some of them are unnecessary for virus replication but seem to have a selective benefit in vivo (niche-specific proteins). The crown-like spikes present on the viral envelope of coronaviruses help them to bind to cells, and in this way they can get inside them and cause the infection. There are different types of diseases caused by coronaviruses. They can infect numerous animal species, causing different diseases such as neurological, gastrointestinal, cardiovascular, and respiratory diseases. Therefore there are different diseases related to coronaviruses with different target groups such as: porcine transmissible gastroenteritis virus (TGEV, pig), procine respiratory coronavirus (PRCV, pig), porcine epidemic diarrhea virus (PEDV, pig), feline infectious peritonitis virus (F1PV, cat), feline coronavirus (FCoV, cat), canine coronavirus (CCOV, dog), rabbit coronavirus ( $\mathrm{RaCoV}$, rabbit), Rat coronavirus (RCoV) or sialodacryoadenitis virus (SDAV, rat and pig), BEV (bovine enteric virus, cattle), Bovine coronavirus (BCoV, livestock), Avian infectious bronchitis virus (IBV, Chicken), Turkey coronavirus (TCoV) or Transmissible gastroenteritis virus (TECoV, turkey), Murine hepatitis virus (MHV, mouse), civet cat CoV (Himalayan palm civet and raccoon dog), and Raccoon dog CoV (Saif et al., 2004 ). Human coronaviruses (HCoV) are divided into two groups of alpha and beta coronaviruses. HCoV-229E, HCoV-NL63 belong to alpha coronaviruses, and $\mathrm{HCoV}-\mathrm{OC} 43, \mathrm{HCoV}-\mathrm{HKU} 1$, severe acute respiratory syndrome (SARS-CoV), Middle East respiratory syndrome (MERS-CoV), and SARS-CoV-2 are in the beta coronaviruses genera (Pyrc et al., 2007). Among these, SARS-CoV and COVID-19 are the 
most recent types of coronaviruses. SARS-CoV encodes a chymotrypsin-like protease (3CLpro), that is also known as the main protease $\left(\mathrm{M}_{\mathrm{pro}}\right)$. This enzyme has an essential role in replication and infection of virus, thus it is an ultimate target for antiviral compounds' designing.

Particularly, the main part of the SARS-CoV genome (first 2/3) consists of the genes responsible for the virus replication that encode 16 non-structural proteins (nsPs), which includes the NTPase/helicase (nsP13). The nsP13 helicase is an important component for replication of the virus which is target for many virus inhibitors (Keum et al., 2013). Angiotensin-converting enzyme 2 (ACE2) has been acknowledged as a practical receptor for SARS-CoV (Li et al., 2003). Coronaviruses can enter the host cell and cause infection by S protein (Spike protein). There are lots of studies about this protein and determination of treatments against the SARS$\mathrm{CoV}$ in particular, and other coronaviruses such as MERS (Hofmann et al., 2004b; Prajapat et al., 2020). These studies can help to invent a drug for newly emerged coronavirus SARS-CoV-2, also called Covid-19 or 2019-nCoV, because they have similar active sites and the same enzymatic mechanisms and also there are high similarities between their genome sequences. In comparison to the SARS-CoV that was emerged 2003, SARS-CoV-2 has a greater transmission capacity. SARS-CoV-2 is also stimulated by binding to ACE2 receptor, so ACE2 blocking agents might be effective way to suppress it (Gralinski et al., 2020). Based on the recent reports about the structure of 3CLpro from SARS-CoV2 and SARS-CoV, the differences between the two main proteases are only in 12 amino acids (Macchiagodena et al., 2020).

Plants are rich sources of metabolites which are valuable compounds for therapeutic purposes. Some of these metabolites possess their antiviral activity by stopping viral proliferations. This can be achieved by different ways such as controlling adsorption of virus, binding to the 
receptors of the host cell, inhibiting the virus fusion to the host cell membrane and by regulating intracellular signals as well (Khan et al., 2005; Min et al., 2018, Hudson et al., 2018).

In this study we aimed to do a review on the effect of the metabolites derived from plants, on different kind of coronaviruses. Binding affinity of these compounds to a specific ligand or receptor of a target protein in virus is studied by molecular docking assay in several studies. A compound which has a lower binding energy is considered as a potential drug candidate (Chandel et al., 2020). Also IC50 value of these metabolites which is half maximal inhibitory concentration against virus is determined in different studies. Plant metabolites that are reviewed in this paper for their anti-coronavirus effects, are secondary metabolites including polyphenols (such as flavonoids, coumarins, stilbenes), alkaloids, terpenoids, organosulfur compounds saponins, saikosaponins, lectins, essential oils, nicotianamine and primary metabolites such as vitamins.

\section{Method}

About 110 accepted and preprint papers on the effect of plants primary and secondary metabolites on various types of coronaviruses and were designated for the review, April 2020. Searching the papers was conducted by the keywords coronaviruses, medicinal plants, plant metabolites, polyphenols, alkaloids, terpenoids, organosulfur compounds, nicotianamine, lectins, essential oils, saponins, herb extracts and vitamins in databases, such as Google Scholar and Science-Direct. Selected papers for this review were the papers published from 1991 to April 2020.

\section{Polyphenols}


Polyphenols are mostly found in plant kingdom and there are many varieties of them. Flavonoids account for a large part of polyphenolic compounds. These compounds have many health benefits due to their antioxidant activity. There are also some studies on their properties, other than antioxidant activity, such as their antimicrobial, antibacterial, antifungal and antiviral activities (Tapas et al., 2008; Song et al., 2005). In addition, there are various types of flavonoids with inhibitory effect against several enzymes such as alpha-glucosidase, and alpha-amylase (Tadera et al., 2006). In this way these compounds can display their antiviral effect. Molecular docking (MolDock) simulation is used to calculate the binding of flavonoids to these enzymes. In docking studies, the higher negative value of docking score is related to the stronger inhibitory ability of the compound. In a study by Nguyen et al., recombinant 3CLpro-a chymotrypsin-like cysteine protease which is vital to virus replication-was expressed in Pichia pastoris GS115 and was used for investigating the effect of seven flavonoids including quercetin, epigallocatechin gallate (EGCG), gallocatechin gallate (GCG), epigallocatechin (EGC), ampelopsin (AMPLS), puerarin, and daidzein on it. Among these flavonoids GCG had the strongest inhibitory effect followed by EGCG, quercetin, AMPLS, diadzein, puerin and EGC. GCG indicated several interaction with amino acid residues in the active site of $3 \mathrm{CL}$ pro. Also galloyl moiety at the $3-\mathrm{OH}$ position of EGCG and GCG, seems to be responsible for their strong 3CLpro inhibitory effect which is not present in AMPLS and EGC. Molecular docking simulation (affinity of the compounds to bind specific receptor on enzyme) indicated that the substrate-binding pocket of 3CLpro is the site that GCG bounds. Daidzein and puerarin, showed little inhibition of 3CLpro. The 3CLpro inhibitory effect of quercetin was 4.96-times higher than AMLSP. The difference between the structures of these polyphenols is the cause for their different inhibition activity. EGC, by having a Hydroxyl group at 5'-position of the B ring, and lacking galloyl moiety and 4 
and 2,3- double bounds, has the lowest inhibitory activity. IC50 of all of the mentioned compounds are shown in (Table. 1). Also inhibitory percentage for AMPLS, EGC, GGC, G, diadzein, puerarin, quercetin, and EGC was 34\%, 85\%, 91\%, 34\%, 33\%, 82\%, and 5.4\%, at 200 $\mu \mathrm{M}$ concentration of them, respectively (Table. 2) (Nguyen et al., 2012). Hesperidin (a flavanone glycoside richly found in the citrus and citrus peel), rutin (an essential nutritional compound mostly found in tea and apples), diosmin (flavonoid mostly found in citrus fruit), apiin (flavonoid in parsely), diacetyl curcumin (synthetic derivative of curcumin), were also displayed as potential inhibitors against protease of COVID-19. According to MolDock binding score, hesperidin had the strongest affinity to block the protease of COVID-19, followed by rutin, diosmin, apiin and diacetylcurcumin (Table. 1). However, all of the mentioned compounds had acceptable binding ability which supports the prospective use of these compounds at first steps of treatment for COVID-19. It can be concluded from this study that consumption of citrus fruits, cherries and apples has the potential to increase immunity to fight against COVID-19 infections (Adem et al., 2020). Results of other study in which a virtual screening was conducted to investigate the effect of some drugs including diosmin and hesperidin on the active sites of SARS-CoV-2 (Covid-19) 3CLpro model, indicated that the flavonoid glycosides diosmin and hesperidin present in citrus fruits are very good substances for blocking the substrate binding site and their MolDock scores are shown in Table. 1. Also hesperidin showed numbers of binding modes, displaying not much adverse reactions (Chen et al 2020). Hesperetin, the aglycone of hesperidin is a bioflavonoid compound which is present in high amount in citrus aurantium and Citri Reticulatae Pericarpium. In a study done by Lin et al, in 2005, seven phenolic compounds, emodin, aloeemodin, chrysophanol (anthraquinones), hesperetin, quercetin (plant flavonol), naringenin (flavanone), and daidzein (isoflavone), were examined for their inhibitory effects on 
the SARS- CoV 3CLpro. Cell-free and cell-based assays were conducted. Only aloeemodin and hesperetin had inhibitory effect on cleavage activity of the 3CLpro in cell-free and cell-based assays which was dose-dependently. These two compounds have shown to have considerably high inhibitory effects on SARS-CoV 3CLpro with IC50 of 132 and $60 \mu \mathrm{M}$ in cell-free assay, respectively. In cell based assay the IC50 values were 366 and $8.3 \mu \mathrm{M}$, respectively. Also diadzein had IC50 of $105 \mu \mathrm{M}$ in cell-free assay but its IC50 was not significant in cell-based assay (Table. 1). Aleoemodin had inhibitory percentage of $65 \%$ at $100 \mu \mathrm{M}$ and for hesperetin and daidzein it was around $82 \%$ and $72 \%$, respectively (Table. 2) (Lin et al., 2005). In another study, hesperetin (which was investigated to have anti-SARS activity, was studied for its ability to inhibit Angiotensin-converting enzyme 2 (ACE2), and also its anti-2019-nCoV activity. Results indicated that hesperetin has the ability to bind to ACE2 with the binding energy of -8.3 kcal/mol (Table. 1), and binding sites where shown to be TYR-613, SER-611, ARG-482, GLU479. It was reported that hesperetin can be strong candidate for 2019-nCoV treatment (Chen and Du. 2020). Another study on the effect of flavonoids on ACE 2, showed that flavonoids present in citrus peels are able to prevent the Covid-19 infection. Specifically, simulated molecular docking results indicated that hesperidin, hesperetin (aglycone of hesperidin) and naringin (flavanone) have stronger binding affinity with the ACE2 receptor. In addition, in vitro and in vivo experiments displays the ability of naringin to inhibit the cytokine storms syndrome stimulated by the Covid-19, through different pathways. According to the results of this study, nobiletin and neohesperidin which are in lower amounts in citrus fruits, can also have anticoronavirus effect, however, neohesperidin had the lowest simulated molecular docking score in compare to other flavonoids studied (Table. 1) (Cheng et al., 2020). In other study hesperetin was discovered to have in vitro antiviral activity against SARS-CoV, beside several other compounds 
including chloroquine (De Clercq et al., 2006). Other polyphenolic compounds like theaflavins which are extracted from black tea and also their fractionated compounds by HPLC (initial peaks (IP), free theaflavin (TF1), theaflavin-3 monogallate (TF2A), theaflavin-3' monogallate (TF2B), and theaflavin-3,3' digallate (TF3)), were tested for their antirotaviral activity. TF1, TF2A, TF2B, and TF3 were the most active compounds having the mean effective concentration (EC50) of $0.125 \mathrm{mg} / \mathrm{ml}$ and TF2A had the least effect with an EC50 of $251.39 \mathrm{mg} / \mathrm{ml}$ against SARS-CoV (Clark et al., 1998). In a study, anthraquinone, emodin and rhein (anthraquinone compounds), chrysin (a flavonoid compound) which are produced in Rheum and Polygonum plants, and promazine which is also a phenolic compound with a similar structure to emodin, were investigated for their inhibitory effect against binding S protein (spike protein) to ACE2. There are several studies on health effects of these compounds (Huang et al., 1991; Chen et al., 2002; Kumar et al., 1998). Results of this study demonstrated that besides disrupting the viral envelope (Sydiskis et al., 1991), emodin and promazine has the potential to block the S protein of SARS-CoV and ACE2 interaction by competing the binding site of S protein with ACE2. On the other hand anthraquinone and 1,4-bis-(1-anthraquinonylamino)-anthraquinone was found to have lower effect on inhibition of the $S$ protein and ACE2 interaction showing that the anthraquinone skeleton don't influence the S protein and ACE2 binding and the side chain has the main role in their inhibitory activity. Chrysin and rhein also had slightly inhibitory effect on mentioned binding with inhibitory percentage of less than $20 \%$ at $200 \mu \mathrm{M}$ concentration. Findings of this study showed that emodin and promazine have the most effect against SARSCOV S protein activity with inhibitory percentage of $50 \%$ and $55 \%$ at concentration of $200 \mu \mathrm{M}$, respectively (Table. 2) (Ho et al., 2006). Baicalein is mainly extracted and purified from the Chinese medicinal plant named Scutellaria baicalensis Georgi. The MolDock binding result 
showed that baicalein have strong binding to the ACE2 enzyme, with binding energy of -8.46 $\mathrm{kcal} / \mathrm{mol}$ (Table. 1), and the potential binding sites are HIS-505, ASN-149, ARG-273. Based on the anti-SARS activity of this compound and its ability to bind to ACE2, it was stated that baicalein can be a strong candidates for 2019-nCoV treatment (Chen and Du. 2020). Scutellarin is another flavone which indicated wide-ranging pharmacological effects. An in vivo study indicated that this compound is able to reduce the expression and activity of ACE in brain tissue and it was reported that it has IC50 value of $48.13 \pm 4.98 \mu \mathrm{M}$ against ACE (Wang et al., 2016; Wang and Ma, 2018). In other study by conducting a molecular docking it was found that scutellarin is able to bind to ACE2, with binding energy of $-14.9 \mathrm{kcal} / \mathrm{mol}$, and the binding sites were GLU-495, UNK-957, ARG-482 (Table. 1). It was stated that this compound can be good candidate for having anti-2019-nCoV activity (Chen and Du. 2020). As mentioned before nsP13, the SARS-CoV helicase, is also vital for viral replication and is regarded as a drug target for SARS-CoV inhibitors. In a study baicalein, scutellarin and myricetin which are natural flavonoids were studied for their inhibitory effect on nsP13. It was shown that baicalein is a strong inhibitor of the ATPase activity of nsP13 protein (with inhibition percentage of $100 \%$ at $10 \mu \mathrm{M}$ (Table. 2)), and its pharmacological activity to inhibit ATPase activity of nsP13 is greater than that of myricetin and scutellarin. IC50 value of baicalein was shown to be $0.47 \pm 0.09 \mu \mathrm{M}$ which was lower than two other flavonoids (Table. 1) (Keum et al., 2013). In another in vitro study, the effect of EGCg which is the major active compound of tea polyphenol with different biological activities on inhibition of the bovine coronavirus (BCV) replication in Madin-Darby bovine kidney (MDBK) cells was explored. At concentrations of less than $10 \mu \mathrm{g} / \mathrm{mL}, \mathrm{EGCg}$ didn't have any cytotoxicity to MDBK cells. Results of this study showed that EGCg has temperature-dependent effect on $\mathrm{BCV}$ and its effect at around $37^{\circ} \mathrm{C}$ (temperature of intestinal 
tract) was better than the temperature of respiratory tract. These results displayed that EGCg has very good anti-BCV activity, it interacts with BCV particles and interferes with the adsorption of BCV to MDBK cells, thus EGCg can be considered as a suitable anti-BCV compound (Matsumoto et al., 2005). In another study, in which secondary metabolites of different medicinal herbs were investigated, results showed that they have inhibitory effects against novel COVID-19 protease. The, dialloyl sulfide from garlic, curcumin in turmeric spices, capsaicin in peppers, limonene and cineol in cardamom, coumarin in liquorice, verbascoside in hedge Nettle, and glucuronic acid in tragacanth were the phenolic compounds in this study that were shown to have inhibitory effect against novel COVID-19 protease. Among these compounds, curcumin had a stronger bond and high affinity with COVID-19 protease (Table. 1) (Mohammadi et al., 2020). In a study by Park et al in 2016, the inhibitory activity of polyphenols from Broussonetia papyrifera, was tested against papain-like protease (PLpro) and 3Lpro of SARS-CoV and MERSCoV. The polyphenols studied, were broussochalcone B, broussochalcone A, 4hydroxyisolonchocarpin, papyriflavonol A, 30-(3-methylbut-2-enyl)-30,4,7-trihydroxyflavane, kazinol A, kazinol B, broussoflavan A, kazinol F, and kazinol J. In overall all of the compounds were more effective against PLpro in compare to 3CLpro. Papyriflavonol A was the most effective inhibitor of SARS-CoV PLpro and its IC50 value was $3.7 \mu \mathrm{M}$. Among them 30-(3-methylbut-2enyl)-30,4,7-trihydroxyflavane was the most effective against MERS-CoV 3CLpro with IC50 of $34.7 \pm 2.0 \mu \mathrm{M}$ and Kazinol $\mathrm{F}$ had the best inhibitory effect on it with IC50 of $39.5 \pm 5.1 \mu \mathrm{M}$. Results of this study showed that B. papyrifera ingredients are potential candidates for being anti-coronaviral (SARS-CoV, and MERS-CoV) agents. The IC50 values of all of these polyphenols, were in the low range (Table. 1) (Park et al., 2017). During an investigation lutein (a caretonoid) was found to be an effective component against wild-type SARS-CoV activity by 
binding to its $\mathrm{S}$ protein with effective concentration (EC50) of $10.6 \mu \mathrm{M}$ (Yi et al., 2004). In a study by Chen et al., the inhibitory activity of quercetin-3- $\beta$-galactoside was investigated against SARS-CoV and it showed IC50 of $42.79 \pm 4.97 \mu \mathrm{M}$ (Table. 1). In this study the binding position of quercetin-3- $\beta$-galactoside for two types of SARS-CoV 3CLpro (the wild-type 3CLpro and its mutated type (3CLpro Q189A)), was also compared and the IC50 of quercetin-3- $\beta$-galactoside on SARS-CoV 3CLpro Q189A was considerably decreased to $127.89 \pm 10.06 \mu \mathrm{M}$ because of the decrease in binding affinity (Table. 1). Moreover, the inhibition percentage of this compound against SARS-CoV 3CLpro, was $41.8 \%$ at $50 \mu \mathrm{M}$ concentraion (Table. 2). Also new derivatives of the quercetin-3-b-galactoside with some chemical variations to the binding components were devised and the results were like this: 1 . Detaching the hydroxy groups of the quercetin moiety which considerably decreases the inhibitory activity 2. Addition of a large sugar on 7-hydroxy of quercetin which can be tolerated 3. Acetoxylation of sugar moiety which stops the inhibitory activity, and 4. Substitution of the galactose moiety with sugars, such as fucose which increased the inhibitory activity (2-fold), arabinose, and glucose, that had no remarkable effect on inhibitory activity (Chen et al., 2006). In other study bioflavonoids extracted from the Torreya nucifera leaves were investigated as possible anti-SARS-CoV 3CLpro. Of the isolated components, amentoflavone was documented as strong inhibitor, showing IC50 value of $8.3 \mu \mathrm{M}$. Also the three flavones (apigenin, luteolin, and quercetin) used as positive control for bioflavonoids and indicated IC50 value of 280.8, 20.2, and $23.8 \mu \mathrm{M}$, respectively (Table. 1). It was shown that there are interactions between the C5 hydroxyl group of amentoflavone with the nitrogen atom of the imidazole group of His163 and $\mathrm{OH}$ group of Leu14, with two hydrogen bonds. These groups belong to S1 site of 3CLpro. In addition, there are hydrogen bonds between the hydroxyl group in the B ring of amentoflavone and Gln189 which belongs to S2 site of 
3CLpro. Also interactions with Val186 and Gln192 can be considered as one of the major bindings with the target site. inhibition percentage results are present in Table. 2 (Ryu et al. 2010). In a study, 720 natural compounds was investigated for their inhibitory effect against 3CLpro. Also the 3CLpro-inhibitory effect of extracts from different kinds of teas, such as black tea, oolong tea, Puer tea and green tea was investigated. Results showed that their inhibitory activities against 3CLpro of Puer and black tea extracts were greater than that of green or oolong tea extracts. Also it was indicated that (-)-epigallocatechin gallte (EGCg), catechin (C), epicatechin gallate (ECg), epicatechin (EC), theophylline (TP), epigallocatechin (EGC), and caffeine are not able to have 3CLpro inhibitory activity. Black tea polyphenols (TF1, TF2 and TF3) also displayed inhibitory activity against 3CLpro. TF3 was the most abundant polyphenol in black tea, followed by TF2A ,TF2B, and TF1. This study has discovered that TF2B, TF3 and tannic acid are effective three compounds to inhibit 3CLpro and their IC50 are less than $10 \mu \mathrm{M}$, but TF2A was not investigated due to its unavailability (Table. 1). These components are presents at high amounts in the extract of black tea. It is difficult to quantify tannic acid's level in green or black tea because it constitutes a wide variety of polymers with mol.wts of 500-3000 Da (Chen et al., 2005). In another study, inhibitory activities of alkylated chalcones and coumarins (flavonoids) which were isolated from Angelica keiskei, were investigated against 3CLpro and PLpro of SARS-CoV in cell-free and cell-based form. Chalcones are abundant in various plants and these compounds are precursors for other components such as flavonoids and alkylated chalcones are the most principal derivatives of them. Of the isolated alkylated chalcones, xanthoangelol E, which has the perhydroxyl group, showed the most possible inhibitory activity against 3CLpro and PLpro with IC50 values of 11.4 and $1.2 \mu \mathrm{M}$, respectively (Table. 1). Moreover, the active chalcones were 2-fold more effective when tested with cell- 
based cis-cleavage assay in compare to the cell-free trans-cleavage assay. Inhibition percentage results are present in Table. 2 (Park et al., 2015). The open-reading-frame 3a of SARS coronavirus has been shown to code a protein which forms a channel with cation-selective ability that can be expressed in the infected cell. The mechanism of virus release is related to the activity of the channel. In a study the flavanols such as kaempferol, kaempferol glycosides, and acylated kaempferol glucoside derivatives were examined for their ability to block the $3 \mathrm{a}$ channel. Glycoside juglanin (with an arabinose residue) was found to be the most effective component to block 3a channel which had an IC50 value of $2.3 \mu \mathrm{M}$ (Table. 1). Kaempferol derivatives which had a rhamnose residue also was likely to be quite effective in blocking $3 \mathrm{a}$ channel. As a conclusion, this study found out that more bioavailable compounds such as emodin and kaempferol (specifically, the glycosides of kaempferol) could be a foundation for the new antiviral drugs exploration. These compounds not only can block the 3 a channel, but also they can interfere with other stages of the viral life cycle (Kaul et al., 1985) and this is an important feature to consider them as a potent antiviral agent (Schwarz et al., 2014). In another in vitro study the inhibitory activities of 64 different natural compounds were investigated against SARS helicase (nsP13). Scutellarin and myricetin showed to restrain the SARS-CoV helicase protein by influencing the ATPase activity, but they didn't have any effect on unwinding activity (inhibition of helicase activity). The IC50 values of myricetin and scutellarein were $2.71 \pm 0.19$ $\mu \mathrm{M}$ and $0.86 \pm 0.48 \mu \mathrm{M}$, respectively. Moreover, the inhibitory percentage of these compounds is $100 \%$ at approximately $10 \mu \mathrm{M}$ concentration of them (Table. 2) (Yu et al., 2012). Stilbene compounds can also be classified as polyphenols and they have a lot of biological activities. These derivatives are assumed to be phytoalexins. In a study (E)-stilbene derivatives with hydroxyl groups were synthesized and in some of them pyridine ring was used in place of one 
benzene ring. Two of these compounds exhibited antiviral effect against SARS in vitro (Li et al., 2006). In a study researchers aimed to show the potential anti SARS-CoV-2 from Citrus sp., Alpinia galangal, Curcuma sp., and Caesalpinia sappan herbs through their binding to 3 protein receptors, by molecular docking study. The studied protein receptors were SARS-CoV-2 protease (PDB ID:6LU7), PD-ACE2 (PDB ID:6VW1), and RBD-S (PDB ID:6LXT). The results indicated that among the compounds present in Citrus sp., hesperidin had the least docking score for all of the protein receptors showing its high affinity to bind to these receptors. Other compounds' inhibitory effects are present in Table. 1. Generally, the results of this study showed that Citrus sp. can be a very good inhibitor of SARS-CoV-2, followed by A. galanga, sappan wood, and Curcuma sp. Also other citrus flavonoids which are present in lemon peel and orange, such as nobiletin, tangeretin, hesperetin, and naringenin, indicated very good affinity to the mentioned receptors, it means that these citrus flavonoids may be able to have antiviral effect (Utomo et al., 2020). In other study the binding energies of different phenolic compounds were studied and among them apigenin-7-glucoside, oleuropein, catechin, curcumin, luteolin-7glucoside, demethoxycurcumin, and epicatechin-gallate showed to have the best activity to consider as COVID-19 Mpro inhibitors (Table. 1). Nevertheless, it was mentioned that more researches are needed to know their potential medicinal use (Khaerunnisa et al., 2020). In other study researchers predicted the SARS-CoV-2 (COVID-19) 3CLpro enzyme and their results showed that in spite of similarities between 3CLpro of SARS-CoV-2 and SARS-CoV, there are some principal differences (Chen et al., 2020) . Thus, researchers are still seeking for a suitable drug to treat Covid-19. In a study nine anitiviral phytochemicals were selected from a broad variety of plant based antiviral agents database, which had shown to have high inhibitory activity against SARS-CoV-2 3CLpro. Nelfinavir (a nocleoside), colistin and prulifloxacin that were 
suggested as natural drugs to be effective against SARS-CoV-2 3CLpro, were considered as controls (Xu et al., 2020; Li et al., 2020). Docking results (Table. 1) showed that 5,7,3',4'tetrahydroxy-2'-(3,3-dimethylallyl) isoflavone which is extracted from the herb named Psorothamnus arborescens, had the highest docking score (-16.35) and also the highest binding affinity $(-29.57 \mathrm{kcal} / \mathrm{mol})$. Generally all of the phenolic compounds they studied, including myricetin, licoleafol (prenylated flavanone), myricetin 3-O-beta-D-glucopyranoside (flavonoid glycoside), (2S)-Eriodictyol 7-O-(6"-O-galloyl)-beta-D-glucopyranoside, and 3,5,7,3',4',5'hexahydroxy flavanone-3-O-beta-D-glucopyranoside (flavonone glycosides), and other phytochemicals such as, amaranthin, methyl rosmarinate, and calceolarioside B (carbohydrate) had higher docking score and binding energies to receptor-binding site of SARS-CoV-2 3CLpro in compare to the control compounds (ul Qamar et al., 2020). In another study, in order to find a potent FDA-approved drug to inhibit COVID-19 Mpro, 19 potent inhibitors were selected from the library of numbers of plant based compounds and results of MolDock analysis of these compounds against COVID-19 Major Protease (6LU7) (Table. 1) showed that phenolic phytochemicals such as aloe-emodin, rhein, withaferin A, enoxacin, and non-phenolics such as withanolide D a naturally occurring steroid, nelfinavir, are considerably suitable inhibitors against COVID-19 Mpro. Results indicated that the binding affinity for nelfinavir, withanolide D and withaferin A were $-8.4,-7.8$ and $-7.7 \mathrm{kcal} / \mathrm{mol}$, respectively and these compounds can be used as potential inhibitors against COVID-19 Mpro, which can be further explored to test against Coronavirus (COVID-19) in pre-clinical and clinical settings (Chandel et al., 2020). There are also some recent in silico studies about the developing a drug for COVID-19 treatment. In one in silico study MolDocking was performed to study 10 potential naturally occurring flavonoids and nonflavonoid compounds against the SARS-CoV-2 S protein and also the results were compared 
with hydroxychloroquine (HCQ) which is an approved drug by FDA. Docking analysis showed that $\mathrm{C}$ - terminal of $\mathrm{S} 1$ and $\mathrm{S} 2$ domain of the $\mathrm{S}$ protein play a key role in binding with these natural compounds. Pterostilbene, kamferol, curcumin, which are phenolic compounds, and HCQ were shown to bind to the C-terminal of S1 domain and the binding energies were -6.7, 7.4, - 7.1, and -5.6 Kcal/mol, respectively. On the other hand the compounds which could bind to the S2 domain of spike protein were resveratrol, apigenin, isorhamnetin, fisetin, quercetin, genistein, luteolin, and their binding energies were -7.9, -7.7, -8.3, -8.5, -8.5, -8.2, and -8.2, $\mathrm{Kcal} / \mathrm{mol}$, respectively. These phenolic compounds were shown to have considerably high binding affinity for S1 and S2 domain of the S protein which are two main important target domains for virus attachment in the host cell and their binding affinities were significantly higher than that of HCQ (Subhash Rane et al., 2020). In another study 15 natural phenolic compounds with antiviral activity was docked with nCov-2019 Mpro. Lopinavir, nelfinavir, and ritonavir were used as positive controls which have been stated to treat the nCov-2019 patients. MolDock score results showed the potentials of these compounds. Bavachinin had the highest docking score with binding energy of $-7.74+/-0.152 \mathrm{Kcal} / \mathrm{mol}$. The next compound with higher docking score $(7.68 \pm 0.021 \mathrm{Kcal} / \mathrm{mol})$ was kaempferol followed by luteolin with docking score of -7.58 $\pm 0.112 \mathrm{Kcal} / \mathrm{mol}$, hinokinin with docking score of $-7.51 \pm 0.021$ and sinigrin with docking score of $-7.49 \pm 0.152 \mathrm{Kcal} / \mathrm{mol}$. Nelfinavir which was used as a positive control had higher docking score $(-7.9 \pm 0.057 \mathrm{Kcal} / \mathrm{mol})$, than bavachinin. The docking score of the two other positive controls (Lopinavir and Ritonavir) were lower than bavachinin and kaempferol being $-7.52 \pm$ $0.022 \mathrm{Kcal} / \mathrm{mol}$, and $-7.42 \pm 0.68 \mathrm{Kcal} / \mathrm{mol}$, respectively (Table. 1) (Ranjan et al., 2020).

In a study a library of flavonoids were applied against SARS-CoV 3CLpro. Among these flavonoids herbacetin, pectolinarin, and rhoifolin could block the activity of SARS-CoV 3CLpro, 
effectively. Docking analysis showed that there are three sites for binding with flavonoids such as S1, S2 and S3' sites. Among the flavonoids, herbacetin (a flavonol), and rhoifolin and pectolinarin (flavones) were found to have noticeable inhibitory activity. The IC50 values of these compounds were $33.17,27.45$ and $37.78 \mu \mathrm{M}$, respectively. Induce-fit docking were done for these compounds and glide scores results for herbacetin, rhoifolin, and pectolinarin were 9.263, -9.565 and -8.054 , respectively. Herbacetin had high binding affinity around the S1 and S2 sites and this was found to be due to the presence of additional 8- hydroxyl group. Moreover, carbohydrate groups present in rhoifolin and pectolinarin compounds were found to occupy the S1 and S2 sites and this was shown to be another cause of high affinity of these glycosylated flavonoids to SARS-CoV 3CLpro (Jo et al., 2020).

\section{Alkaloids}

Plants produce around 12,000 alkaloids, which can be classified into different groups based on the structures of their carbon skeletal. There are several studies about the antiviral activity of different alkaloids (Özçelik et al., 2011; Peng et al., 2013; Moradi et al., 2017).

In a study researchers aimed to study the antiviral activities of alkaloids such as tetrandrine (TET), fangchinoline (FAN), and cepharanthine (CEP) against HCoV-OC43. These compounds considerably inhibited cell death caused by the virus at the early phases of infection. They had a considerable effect on suppressing the replication of $\mathrm{HCoV}-\mathrm{OC} 43$ and also they are able to inhibit the viral S and $\mathrm{N}$ protein expression (Kim et al., 2019).

Emotin is one of the major alkaloids that is found in ipecacuanha or ipecac root. In other study emetin, was studied to cure COVID-19. Among 290 anti-MERS and anti-SARS agents, emetine had stated to have the lowest half-maximal effective concentration (EC50). Also, it was stated 
that due to the lower EC50s of emetine against coronaviruses, in compare to Entamoeba histolytica, it can be considered as an anti-coronavirus agent. Investigations about emetine indicated that this compound can reach therapeutic concentrations inside the lungs so ipecac, emetine, and other analogues can be considered as possible treatment options, especially if in vitro studies approve viral sensitivity (Bleasel et al., 2020).

Mongolia, is a traditional Mongolian medicine generally used for treating tumor and cancer. Main compounds in Agsirga are alkaloids, organic acids, stilbenes, flavonoids saponins, etc, and among these compounds steroidal alkaloids are the major active components. Molecular docking technology results showed that these compounds have the ability to block the binding between Sprotein of 2019-nCoV and middle bridge, namely D30, H34 of ACE2 protein (Table. 1). This research provided a theoretical and methodological reference for future researches about using Mongolian medicine for 2019-nCoV treatment (Cheng et al., 2020).

In a study it was indicated that tryptanthrin (a plant alkaloid) which is among the major active compounds in S. cusia leaf is able to inhibit HCoV-NL63 replication independently. Findings showed that tryptanthrin has a greater antiviral activity against HCoV-NL63 in compare to indigodole B which has an extra ethyl moiety at C5a in the place of double bond in tryptanthrin. In addition, in particular, tryptanthrin changes the antigenic configuration of viral $\mathrm{S}$ proteins and in this way it inhibits the PLP2's cleavage activity (with IC50 of less than $0.1 \mu \mathrm{M}$ ). Therefore, tryptanthrin can be used as one of the successful compounds against human coronaviruses. Notably, tryptanthrin and indigodole B demonstrated strong virucidal activity with IC50 of 0.06 $\mu \mathrm{M}$ and $2.09 \mu \mathrm{M}$, respectively (Tsai et al., 2020).

\section{Terpenoids}


Terpenoids, which are also called isoprenoids, are the most abundant natural products with various structures that are found in many plants and have a many pharmacological properties (Ludwiczuk et al., 2017).

In a cell-based study 20 phytocompounds were selected to investigate their inhibitory activity against $3 \mathrm{Cl}_{\text {pro }}$ of SARS- CoV. Curcumin, betulinic acid, and savinin exhibited inhibitory activities on 3CLpro and their IC50 values were 40, 10, and 25, respectively. Contrarily, betulonic acid and hinokinin, analogues of betulinic acid and savinin, had IC50 values of more than 100 $\mu \mathrm{M}$. Betulinic acid and savinin had competitive inhibitory activity on 3CLpro because of the multiple hydrogen bonds that they form with specific amino acid residues present at the active site of the enzyme (Wen et al., 2007). In other study the activity of 23 compounds from the ethanolic extract of E. neriifolia leaves, were studied against HCoV. Among these compounds, 22 of them were triterpenoids and one of them was flavonoid glycoside. of these compounds, $3 \beta$ Friedelanol exhibited stronger antiviral activity in compare to actinomycin D which was the positive control, and this suggests the significance of the friedelane skeleton as a possible stage for evolving new anti-HCoV-229E drugs (Chang et al., 2012). In an in silico study, a library of plant based compounds with antiviral activity was studied for their activity against S glycoprotein 6vsb and Mpro 6lu7 targets of SARS-CoV-2 with the PyRX software. Six top compounds such as scopadulcic acid (a diterpenoid), dammarenolic acid (a triterpenoid), baicalin, sylibinin or silymarin (a flavonolignan), solanidin (steroidal glycoalkaloid), naringenin, oleanane with binding energies between -9 to $-9.6 \mathrm{Kcal} / \mathrm{mol}$ were selected for molecular docking analyses against 6lu7. Generally, the two diterpenoid and triterpenoid compounds, scopadulcic acid and dammarenolic acid exhibited the strongest activity against SARS-CoV-2 S glycoprotein 
6vsb and Mpro 6lu7 targets, respectively, followed by solanidin and sylibinin (Table. 1) (Ubani et al., 2020).

Resveratrol which is a stilbene and belong to phenolic compounds family, was studied for its activity against MERS-CoV and was shown to be effective at both entry and post entry step of infection. Their investigations demonstrated that resveratrol is able to inhibit nucleocapsid expression of MERS-CoV also it can reduce the vero E6 cell death as a result of MERS-CoV infection at concentration range from $125-250 \mu \mathrm{M}$. Moreover, this compound could reduce the MERS-CoV RNA expression and it can suppress this RNA replication, however for this purpose high concentrations of resveratrol is required. Generally, the could firmly confirm resveratrols' anti-MERS activity (Lin et al., 2017).

\section{Saponins and saikosaponins}

Glycyrrhizin is another phytochemical belong to saponins, which is derived from Chinese Medicine herb licorice root (Glycyrrhiza radix). Glycyrrhizin was shown to be a good treatment for SARS by influencing the viral adsorption and penetration before (Cinatl et al., 2003). In other study docking results demonstrated that glycyrrhizin has the potential to bind to ACE2 with binding energy of -9 kcal/mol, and the binding sites were ARG-559, GLN-388, ARG-393, ASP30. It was shown that this phytochemical might be a potential candidate to have anti-2019-nCoV activity (Chen and Du, 2020). In a study 15 derivatives of glycyrrhizin were studied for their anti-SARS effect and was found that presence of 2-acetamido- $\beta$-D-glucopyranosylamine in the glycoside chain of glycyrrhizin cause a 10-fold increase in anti-SARS-CoV activity in compare to glycyrrhizin with EC50 of $40 \pm 13 \mu \mathrm{M}$. Glycyrrhizin amides and conjugates of it with two of 
the amino acid residues and a free $30-\mathrm{COOH}$ had caused up to 70 -fold increase in its anti-SARSCoV activity with EC50 of 5 to $50 \mu \mathrm{M}$ but also increased its cytotoxicity (Hoever et al., 2005). Saikosaponins A, B2, C and D which are saponin glycosides were also studied for their antiSARS-CoV effect. Results displayed that all of the examined compounds showed antiviral activity at concentrations of $0.25-25 \mu \mathrm{mol} / \mathrm{L}$, and saikosaponin B2 had the highest inhibitory activity with IC50 of $1.7 \pm 0.1 \mathrm{mmol} / \mathrm{L}$. Moreover, it had inhibitory effect on viral penetration and attachment (Cheng et al., 2006).

\section{Organosulfur Compounds}

Garlic essential oil is very good source of organosulfur compounds which are known for their therapeutic properties. Also these compounds are expected to interact with ACE2 protein's amino acids. In a study, researchers investigated organosulfur compounds' effect against SARS-CoV-2. Results of MolDock study showed that allyl disulfide and allyl trisulfide which are the most abundant compounds in garlic essential oil, have the best binding affinity to the 6LU7 protein of SARS-Cov-2, followed by diallyl tetrasulfide. Trisulfide, 2-propenyl propyl and diallyl tetrasulfide was found to have the best interaction with ACE2 receptor. Moreover, organosulfur compounds in garlic showed stronger interaction with 6LU7. Generally, Results exhibited that the essential oil extracted from garlic is a precious natural antivirus source (Thuy et al., 2020).

\section{Lectin}

Lectins are proteins which can bind to carbohydrates to form glycoproteins. They can agglutinate cells and in this way lead to precipitation of glycoconjugates (Vasconcelos and Oliveira, 2004). 
In addition to this, they can make binds with carbohydrates, reversibly. Lectin proteins have been showed to make hydrophobic and hydrogen bonding and van der Waals interactions (Singh, et al., 1999). Lectines are not immunoglobulins and they do not change the functional properties of carbohydrates binded (Lagarda-Diaz et al., 2017).

Generally, lectins can be divided into seven different protein groups (Damme et al., 1998). It has been revealed that these compounds have strong effect on commonly known HIV replication in lymphocyte cell cultures (Hann, 1989). As a result of numerous research, it was revealed that, lectin proteins attack directly to the virus cell and prevent HIV fusion (Dudley et al., 2016). In addition HIV, it was reported that plant lectins have inhibitory effects on various virus species such as respiratory syncytial and influenza A virus infections which threat human health (Balzarini, 2007). Moreover, plant lectins were proved to have strong impact on SARS-CoV (Ritchie et al., 2010). Glycan binded lectin proteins have inhibitory effect on coronavirus infectivity. In the scope of wide reserach, 33 different plant lectins having diverse specificities were studied for their antiviral acitivity on SARS-CoV. According to the outcomes, two third of species had strong antiviral effect on SARS CoV (Keyaerts et al., 2007). Results also revealed that mannose specific lectin proteins have stronger antiviral effect on SARS-CoV (Mazalovska and Kouokam, 2018). In order to see the effect of mannospecific lectin, mannosespecific lectin of amaryllis (HHA) was used for further experiments. According to the results, it was observed that HHA added infections had one log reduced viral load in compare to the positive control. Furthermore, lectin led to 5 hours delay on SARS-CoV infected cell growth (Keyaerts et al., 2007).

Generally, replication of coronaviruses are prevented by plant based lectins within the cell culture (van der Meer et al., 2007). Specifically, mannose-based HHA, the GlcNAc-specific 
agglutinin NICTABA, (GlcNAc)n-specific agglutinin, and Urtica dioica agglutinin (UDA) are found as potential coronavirus inhibitors as a result of in-vitro studies (Barnard and Kumaki, 2011).

Griffithsin (GRFT), a specific type of lectin obtained from Griffithsia sp., has the ability to decrease viral infections in humans. It can act as strong inhibitor of SARS-CoV infection (O'Keefe et al., 2010). GRFT prevent the entrance of genetic information to the host cell and spike protein function. Therefore, it blocks coronavirus infection at the initial stage (Carr et al., 2016). It was reported that GRFT have also significant functional effect on MERS-CoV. However, GRFT inhibited viral function during entry to the cell (Zaki et al., 2012). Another patient study was performed to see the antiviral effect of mannose binding lectin (MBL) on SARS-CoV. Their investigations showed that MBL is able to bind to SARS-CoV, in vitro, in a dose- and calcium-dependent and also mannan-inhibitable manner, showing that carbohydrate identification domains of MBL are responsible for its binding. These findings signifies the potential role of MBL in defense against SARS-CoV infection by binding to the $\mathrm{S}$ protein of SARS-CoV before releasing of a particular antibody (Ip et al., 2005).

\section{Herb extracts and essential Oils}

Essential oils (EOs) have widely used for thrapeutic purposes due to their antiviral, antimicrobial and antifungal activities. Majorly, these secondary metabolites of aromatic herbs and plants show effective inhibition acitivities against viral infections. They are used to heal non-infectious and infectious diseases caused by bacteria and viruses (Mickymaray, 2019). Extraction of active secondary metabolites are achieved by using diverse techniques such as steam distillation, ultrasound or microwave methods, cold pressing or maceration (Chouhan, 2017). The main 
phytochemical compounds of EOs can be given as monoterpenes, phenylpropanoids and oxygenated sesquiterpenes. They are widely used in pharmacological and medical fields (D'agostino, et al., 2019). Essential oils are known as volatile compounds which constitute secondary metabolites such as terpenes, aromatic compounds and oxygenated derivatives (Goodger et al., 2016 ). Essential oils have been accepted as plant-based antiviral molecules and used in prevention of some human infected viruses such as immunodeficiency virus, herpes simplex, hepatitis B (Cos et al., 2006; Schnitzler et al., 2008). According to study by Schuhmache et al., essential oils can distrupt the membrane of SARS-CoV due to their lipophilic nature or treat viral envelope proteins in the host cell (Schuhmache et al., 2003). Resylts of a study on the Peels of Citrus sinensis (Cs), Anthemis hyalina (Ah), and Nigella sativa (Ns) effect on coronavirus showed that TRP genes' expression is down-regulated, in the cells infected with $\mathrm{CoV}$ and also the cells which were treated with herb extracts. Moreover, the virus loads were decreased after extract treatments (Ulasli et al., 2013). Another study about the antiviral activity of essential oil from eucaliptus against coronavirus has been conducted by using eucalyptol $(1,8$ cineole) which is known as major component of eucalyptus oil. It has found that eucalyptol could be potential antiviral compound for COVID-19. Chemical structure of eucalyptol which is mainly composed of Hydroxy $(-\mathrm{OH})$, ketone $(=\mathrm{O})$ and ether groups $(-\mathrm{O})$ are the responsible groups for inhibition of COVID-19 (Sharma, 2020). In an in vitro and in vivo study about the effect of a natural product including a synergistic blend of plant based oleoresins and essential oils in a liquid emulsion labeled as QR448(a) against IBV, it was shown that it was effective against IBV irrespective of serotype. The QR448(a)'s effect was more considerable on cell free based study. These results were important because they can be used for other enveloped respiratory viruses such as other coronaviruses (Jackwood et al., 2010). Also there are studies on 
the plant extracts from Astragalus mongholicus, Houttuynia cordata, Alium sativum, and Sambucus nigra which demonstrated that they are effective against both IBV coronavirus replication and amount of viruses before inhibition (Mohajer Shojai et al., 2016; Chen et al., 2014; Zhang et al., 2018; Yin et al., 2011). Houttuynia cordata had demonstrated to have antimurine coronavirus effect with IC50 of $0.98 \mu \mathrm{g} / \mathrm{mL}$ (Chiow et al., 2016). Moreover, it was shown that it has inhibitory activity on 3CLpro of SARS-CoV (Lau et al., 2008). In addition, extracts of Satureja (S.) montana, Origanum (O.) vulgare, Mentha (M.) piperita, Melissa (M.) officinalis, Thymus (T.) vulgaris, Hyssopus (H.) officinalis, Salvia (S.) officinalis and Desmodium (D.) canadense have been discovered as natural antiviral against several IBV coronavirus. However, M. piperita, T. vulgaris and D. canadense extracts had strogenst antiviral effect. EC50 of the extracts were reported between 0.003 and $0.0076 \mu \mathrm{g}$ (Lelešius et al., 2019). In another in silico study The present in silico study molecular docking studies was conducted to determine the effect of Jensenone which is compound in essential oil from eucalyptus oil, on COVID-19 Mpro. Results showed that, Jensenone can make complexes with Mpro through hydrophobic, hydrogen bond, and strong ionic interactions. Based on the dock score results, these complexes have 4 different poses with docking scores ranging from -4.8 to -5.5 , and the one with highest negative values indicated maximum binding affinity (Table.1). Thus, this compound may be a possible treatment to COVID-19 (Sharma and Kaur, 2020). In a study by Kim et al., medicinal extracts of, Meliae cortex, Coptidis rhizoma, Sophora subprostrata radix, Phellodendron cortex, Cimicifuga rhizoma herbs, were investigated for their anti- MHV effect and Torilis fructus, Sophorae radix, Acanthopanacis cortex and, Sanguisorbae radix were selected as potential candidate to cure coronaviruses. EC50 values of these extracts were from 2.0 to $27.5 \mu / \mathrm{ml}$ (Kim et al., 2010). Lycoris radiata, Artemisia annua, Pyrrosia lingua, and Lindera aggregate were 
other herbal extracts studied for their anti-SARS-CoV effect with EC50 of $2.4( \pm 0.2), 34.5( \pm 2.6)$, $43.2( \pm 14.1)$, and $88.2( \pm 7.7) \mu / \mathrm{ml}$, respectively. Also alkaloid isolated from Lycoris radiata (lycorine) had EC50 of $15.7( \pm 1.2) \mathrm{nM}$, whereas commercial lycorine has EC50 of $48.8( \pm 3.6)$ nM (Li et al., 2005).

\section{Vitamins}

Micronutrients and phytonutrients found in fruits and vegetables mainly vitamins (vitamin A,C and E) are responsible for immune functions (Calder et al., 2020). Recently, it has been revealed that vitamins are also effective options for COVID-19 infections (Conti et al., 2020). There are numerous micronutrients, mainly vitamin A, C, D and E which show antiviral properties against coronavirus. It might be sufficient to use these nutrients without any treatment or medical aid. However, these nutrients are needed to be focused, in order to prevent viral infections such as SARS-CoV-2 (Gasmi et al., 2020). A couple of studies and systematic reviews have showed that vitamin D can provide protection against SARS (Calder et al., 2020). Vitamin D has been accepted as an important tool to provide antiviral immunity and immunoregulatory defense (Gasmi et al., 2020). It has inhibitory mechanisms by reducing infection risk and death (Grant et al., 2020). It can help to protect important tight junctions such as gap junction and adherens junctions like E-cadherin (Schwalfenberg, 2011). Vitamin D increases cellular immunity by decreasing cytokine storm (Grant et al., 2020). Innate immune system induced cytokine storm, creates inflammatory and anti-inflammatory cytokines in COVID-19 cases. Therefore, there is a relation between vitamin D mechanism and immunity of patients (Huang et al., 2020). It has been also added that for people who are at risk of COVID-19, high concentrations of 25(OH)D such as $40-60 \mathrm{ng} / \mathrm{ml}(100-150 \mathrm{nmol} / \mathrm{l})$ should be applied in order to get effective treatment 
results (Grant et al., 2020). Furthermore, vitamin D might decrease production of antiinflammatory Th1 cytokines like interferon and tumor necrosis (Sharifi et al., 2019). By introduction of vitamin D, expression of pro-inflammatory cytokines can be diminished and antiinflammatory cytokines by macrophages can be enhanced (Gombart et al., 2020). Vitamin D is also effective on adaptive immunity (Cantorna, 2010). 1,25(OH)2D3 can inhibit the responses coming from T helper cell type 1 (Th1). Moreover, 1,25(OH)2D3 can slow down the activities of T regulatory cells, so inflammatory activities can be prevented (Jeffery et al., 2009).

Evidences of coronavirus inhibited effects of vitamin D can be emphasized by analyzing casefatality rates based on age or disease comorbidity and lower concentrations of $25(\mathrm{OH}) \mathrm{D}(\mathrm{Gasmi}$ et al., 2020). Moreover, studies have revealed that elderly people having vitamin D deficiency have required hospitalized treatment for diseases (Elliott et al., 2003). Vitamin A has been predicted to show effective antiviral properties. It has been approved that vitamin A deficient patients are more prone to viral infections including respiratory syncytial viruses (Mcgill et al., 2019). There is no exact proof that shows antiviral impact of vitamin A on coronavirus. However, it has been verified that vitamin A has immune supporting roles such as cytokine expression, antibody production, cell killing like macrophages or monocytes (Jee et al., n.d.). Vitamin A is the first plant based vitamin which has three different forms within the body like, retinol, retinal and retinoic acid. Intake of vitamin A can provide protections against lung diseases, malaria, diarrheal disease and measles (Mantay, 2020). It has been accepted as antiinfective against various viral infections such as human immunodeficiency virus (HIV) (Zhang and Liu, 2020; Villamor et al., 2002). In addition, it has been reported that fat soluble vitamin A deficiency may result in higher susceptibility to coronaviruses such as bovine coronavirus or bronchitis coronavirus (IBV). It has been detected that vitamin A deficient chicken fed diet 
results in coronavirus infection in chickens (Mcgill et al., 2019). Vitamin A inhibited measles replication of innate immune system. Additionally, uninfected bystander cells were made immune against coronavirus infection. Therefore, it has been approved that vitamin A can be used as treatment method for novel coronavirus (COVID-19) (Zhang and Liu, 2020). Water soluble vitamin B which is known as part of coenzymes are also effective on coronaviruses. Specifically, vitamin B2 (riboflavin) is essential for energy metabolism of cells (Powers, 2003). It had been reported that vitamin B2 may decrease the titer of MERS-CoV within human plasma (Keil et al., 2016). Moreover, vitamin B3 (nicotinamide) might be used as a treatment for ventilator induced lung injuries by inhibiting the neutrophil infiltration of the lungs, but conversely it can cause hypoxemia (Jones et al., 2015). Generally, it has been approved that vitamin B groups can be selected as a supporting treatment for COVID-19 and deficiencies in this vitamin can cause weakness in human's immune system (Zhang and Liu, 2020).

Moreover, it has been found that vitamin $\mathrm{C}$ may also be used as treatment for respiratory diseases (Hemilä, 2017). Ascorbic acid (water soluble vitamin C) plays a vital role in collagen synthesis and it is accepted as natural antioxidant. It is also known as protector against respiratory infections such as coronavirus (Hemilä, 2003). It has been reported that vitamin C had the effect to enhance resistance of chick embryo tracheal organ cultures against coronavirus infection (Atherton et al., 1978). Furthermore, trials on humans have been revealed that vitamin $\mathrm{C}$ usage has declined respiratory tract infections. Therefore, it can be deduced that vitamin $\mathrm{C}$ may decrease respiratory tract symptoms in recent COVID-19 infection (Zhang and Liu, 2020). Fat soluble vitamin E containing tocopherols and tocotrienols also has significant effect to decrease oxidative stress by binding to free radicals due to its antioxidant property (Galmés et al., 2018). It has been reported that vitamin E deficiency might lead to myocardial injuries 
caused by RNA viruses (Beck and Suppl, 1997). It can be deduced that vitamins can be additional supplements alternatives due to their immune supporting roles and can be used to decrease risk of coronavirus infections (Grant et al., 2020).

\section{Nicotianamine}

Nicotianamine (a Fe chelator in plants) which is rich in soybean was investigated for its inhibitory effect on ACE2 and was shown to inhibit the ACE2 activity, with IC50 value of 84 nM (Takahashi et al., 2015). Molecular docking of nicotianamine was conducted to determine its affinity to ACE2 enzyme, it was shown that binding energy of nicotianamine to ACE2 is -5.1 $\mathrm{kcal} / \mathrm{mol}$ (Chen and Du. 2020). 


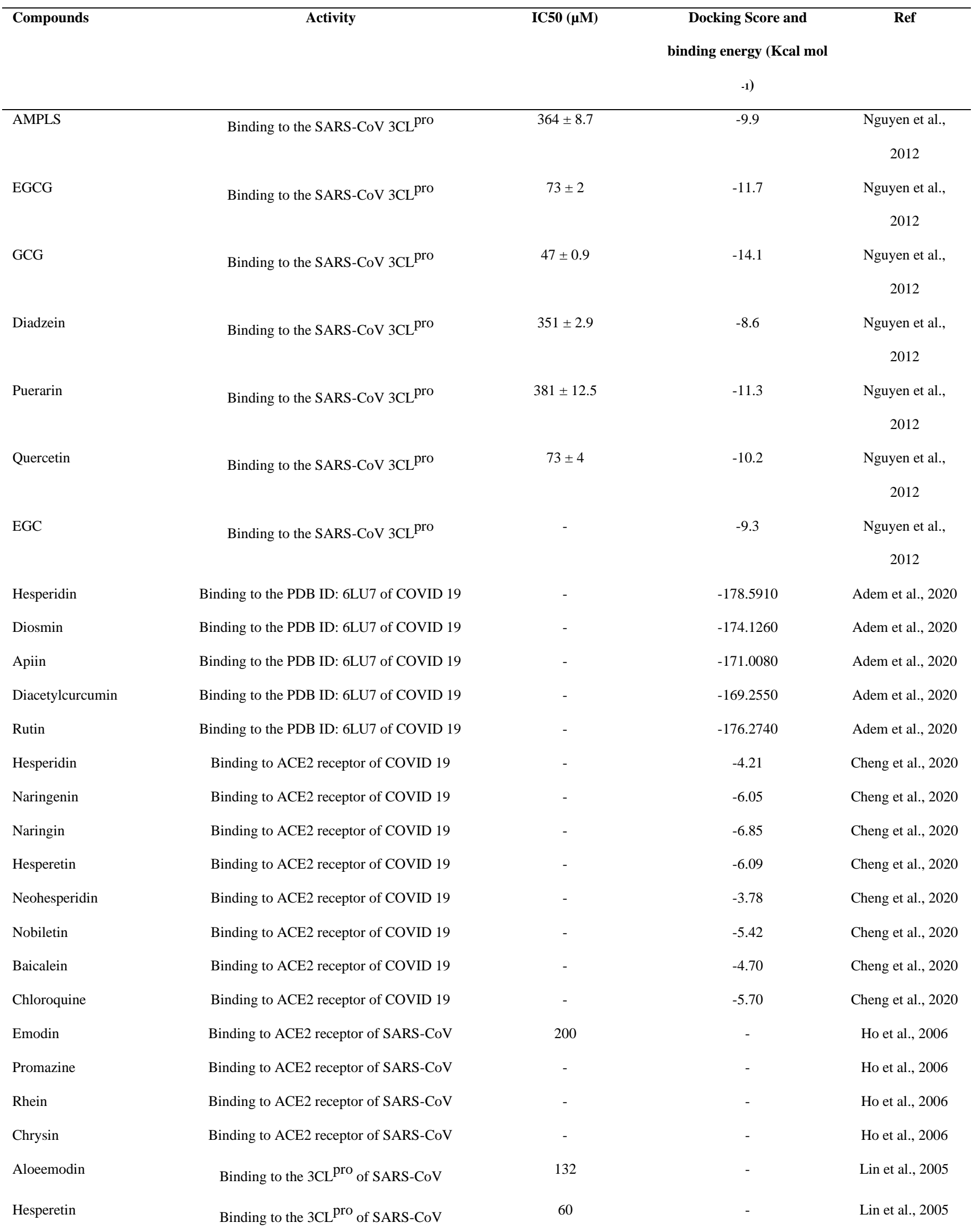


Diadzein

Baicalein

Scutellarein

Myricetin

Broussochalcone B

Broussochalcone A

4-hydroxyisolonchocarpin

Papyriflavonol A

30-(3-methylbut-2-enyl)30,4,7-trihydroxyflavane

Kazinol A

Kazinol B

Broussoflavan A

Kazinol F

Kazinol J

Isoliquiritigenin

Kaempferol

Quercetin

Quercetin- $\beta$-galactoside

Quercetin-3- $\beta$-galactoside

Quercetin-3- $\beta$-galactoside

Amentoflavone

Bilobetin

Ginkgetin

Sciadopitysin

18-hydroxyferruginol

Hinokiol

Ferruginol

18-oxofer- ruginol

$$
\text { Binding to the } 3 \mathrm{CL}^{\text {pro }} \text { of SARS-CoV }
$$

Binding to ATPase domain of nsP13 of

\section{SARS-CoV}

Binding to ATPase domain of nsP13 of

\section{SARS-CoV}

Binding to ATPase domain of nsP13 of

\section{SARS-CoV}

Binding to PLpro and 3CLpro of SARS-CoV

Binding to PLpro and 3CLpro of SARS-CoV

Binding to PLpro and 3CLpro of SARS-CoV

Binding to PLpro and 3CLpro of SARS-CoV

Binding to PLpro and 3CLpro of SARS-CoV

Binding to PLpro and 3CLpro of SARS-CoV

Binding to PLpro and 3CLpro of SARS-CoV

Binding to PLpro and 3CLpro of SARS-CoV

Binding to PLpro and 3CLpro of SARS-CoV

Binding to PLpro and 3CLpro of SARS-CoV

Binding to PLpro and 3CLpro of SARS-CoV

Binding to PLpro and 3CLpro of SARS-CoV

Binding to PLpro and 3CLpro of SARS-CoV

Binding to PLpro and 3CLpro of SARS-CoV

Binding to the SARS-CoV 3CLpro

Binding to the SARS-CoV 3CLpro Q189A

Binding to the $3 \mathrm{CL}_{\mathrm{pro}}$ of SARS-CoV

Binding to the 3CLpro of SARS-CoV

Binding to the 3CLpro of SARS-CoV

Binding to the 3CLpro of SARS-CoV

Binding to the 3CLpro of SARS-CoV

Binding to the 3CLpro of SARS-CoV

Binding to the 3CLpro of SARS-CoV

Binding to the 3CLpro of SARS-CoV
105

$0.47 \pm 0.09$

$2.71 \pm 0.19$

$0.86 \pm 0.48$

\section{CLpro}

PLpro

$$
57.8 \pm 0.5 \quad 11.6 \pm 0.7
$$

$88.1 \pm 13.0 \quad 9.2 \pm 1.5$

$202.7 \pm 3.9 \quad 35.4 \pm 11.3$

$103.6 \pm \quad 3.7 \pm 1.6$

17.4

$30.2 \pm 6.8 \quad 35.8 \pm 6.7$

$84.8 \pm 10.4 \quad 66.2 \pm 6.8$

$233.3 \pm 6.7 \quad 31.4 \pm 2.9$

$92.4 \pm 2.1 \quad 30.4 \pm 5.5$

$43.3 \pm 10.4 \quad 27.8 \pm 2.5$

$64.2 \pm 1.7 \quad 15.2 \pm 1.6$

$61.9 \pm 11.0 \quad 24.6 \pm 1.0$

$116.3 \pm 7.1 \quad 16.3 \pm 2.1$

$52.7 \pm 4.1 \quad 8.6 \pm 3.2$

$128.8 \pm 4.5 \quad 51.9 \pm 5.5$

$42.79 \pm 4.97$

$127.89 \pm 10.06$

$8.3 \pm 1.2$

$72.3 \pm 4.5$

$32.0 \pm 1.7$

$38.4 \pm 0.2$

$220.8 \pm 10.4$

$233.4 \pm 22.2$

$49.6 \pm 1.5$

$163.2 \pm 13.8$
Lin et al., 2005

Keum et al., 2013

Keum et al., 2013

Keum et al., 2013

Park et al., 2017

Park et al., 2017

Park et al., 2017

Park et al., 2017

Park et al., 2017

Park et al., 2017

Park et al., 2017

Park et al., 2017

Park et al., 2017

Park et al., 2017

Park et al., 2017

Park et al., 2017

Park et al., 2016

Park et al., 2017

Chen et al., 2006

Chen et al., 2006

Ryu et al., 2010

Ryu et al., 2010

Ryu et al., 2010

Ryu et al., 2010

Ryu et al., 2010

Ryu et al., 2010

Ryu et al., 2010

Ryu et al., 2010 
O-acetyl-18-

hydroxyferruginol

Methyl dehydroabi- etate

Isopimaric acid

Kayadiol

Diallyl Disulfide

Curcumin

Capsaicin

Limonene

Thymol

Coumarin

Verbascoside

glucuronic acid

Diosmin

Hesperidin

3-Isotheaflavin-3-gallate

(TF2B)

Tannic acid

Oolong tea extract

Green tea extract

Black tea extract

Puer tea extract

Caffeine

Theophylline

Catechin (C)
Binding to the $3 \mathrm{CL}_{\text {pro }}$ of SARS-CoV

Binding to the $3 \mathrm{CL}_{\text {pro }}$ of SARS-CoV

Binding to the 3CLpro of SARS-CoV

Binding to the 3CLpro of SARS-CoV

Inhibiting COVID_19 protease

Inhibiting COVID_19 protease

Inhibiting COVID_19 protease

Inhibiting COVID_19 protease

Inhibiting COVID_19 protease

Inhibiting COVID_19 protease

Inhibiting COVID_19 protease

Inhibiting COVID_19 protease

Binding to the active sites of SARS-CoV-2

$$
\text { 3CLpro model }
$$

Binding to the active sites of SARS-CoV-2

$$
\text { 3CLpro model }
$$

Binding to the $3 \mathrm{CL}_{\text {pro }}$ of SARS-CoV

Binding to the $3 \mathrm{CL}_{\text {pro }}$ of SARS-CoV

Binding to the 3CLpro of SARS-CoV

Binding to the 3CLpro of SARS-CoV

Binding to the $3 \mathrm{CL}_{\mathrm{pro}}$ of SARS-CoV

Binding to the 3CLpro of SARS-CoV

Binding to the 3CLpro of SARS-CoV

Binding to the 3CLpro of SARS-CoV

Binding to the $3 \mathrm{CL}_{\mathrm{pro}}$ of SARS-CoV
$128.9 \pm 25.2$

$207.0 \pm 14.3$

$283.5 \pm 18.4$

$137.7 \pm 12.5$

$-127$

$-107$

$-54$

$-55$

$-10$

$-10$

Chen et al 2020

Chen et al., 2005

Chen et al., 2005

Chen et al., 2005

Chen et al., 2005

Chen et al., 2005

Chen et al., 2005

Chen et al., 2005

Chen et al., 2005

Chen et al., 2005 
Epigallocatechin (EGC)

Epigallocatechin gallte (EGCg)

Epicatechin (EC)

Epicatechin gallate (ECg)

Theaflavin (TF1)

Theaflavin-3-gallate, TF-2a and Theaflavin-3'-gallate,

TF-2b mixture (TF2)

Theaflavin-3,3'-digallate

(TF3)

Isobavachalcone

4-hydroxyderricin

Xanthoangelol

Xanthoangelol F

Xanthoangelol D

Xanthoangelol E

Xanthoangelol B

Xanthoangelol G

Xanthokeistal A

Betulonic acid

Betulinic acid

Hinokinin

Savinin

Curcumin
Binding to the $3 \mathrm{CL}_{\text {pro }}$ of SARS-CoV

100

100

100

100

Binding to the 3CLpro of SARS-CoV

Binding to the $3 \mathrm{CL}$ pro of SARS-CoV

Binding to the 3CLpro of SARS-CoV

9.5
Binding to the 3CLpro of SARS-CoV

Chen et al., 2005

Chen et al., 2005

Chen et al., 2005

Chen et al., 2005

Chen et al., 2005

Chen et al., 2005

Chen et al., 2005

Park et al., 2015

Park et al., 2015

Park et al., 2015

Park et al., 2015

Park et al., 2015

Park et al., 2015

Park et al., 2015

Binding to the 3CLpro and PLpro of SARS-

$22.2 \pm 6.5$

$11.7 \pm 0.3$

\section{$\mathrm{CoV}$}

Binding to the 3CLpro and PLpro of SARS-

$129.8 \pm 1.3$

$46.4 \pm 7.8$

Park et al., 2015

\section{$\mathrm{CoV}$}

Binding to the 3CLpro and PLpro of SARS-

$44.1 \pm 1.3$

$21.1 \pm 5.6$

Park et al., 2015

\section{$\mathrm{CoV}$}

Binding to the 3CLpro of SARS-CoV

10

Wen et al., 2007

Binding to the 3CLpro of SARS-CoV

$>100$

Wen et al., 2007

Binding to the 3CLpro of SARS-CoV

$>100$

Wen et al., 2007

Binding to the 3CLpro of SARS-CoV

25

Wen et al., 2007

Binding to the 3CLpro of SARS-CoV
40
Wen et al., 2007 
Tetrandrine

Fangchinoline

Ceparanthine

Emetine

Hupehemonside

Imperialine-3- $\beta$-D-

glucoside

Pseudojervine

Zhebeininoside

Veratroylzygadenine

Zhebeinone-3- $\beta$-D-

glucoside

Mulberroside E

Hupehenisine

Verdine

Verticinone-3- $\beta$-D-

glucoside

(E)-Resveratrol 3,5-O- $\beta$ -

diglucoside

Peimisine

15-O-(2-Methylbutanoyl)-

3- O-veratroylprotoverine

3-Acetylzygadenine
Supressing HCoV-OC43 replication and

viral $\mathrm{S}$ and $\mathrm{N}$ protein expression

Supressing HCoV-OC43 replication and viral $\mathrm{S}$ and $\mathrm{N}$ protein expression

Supressing HCoV-OC43 replication and

viral $\mathrm{S}$ and $\mathrm{N}$ protein expression

MERS-CoV replication inhibitor

Binding to ACE2 receptor of 2019- nCoV

Binding to ACE2 receptor of 2019- nCoV

Binding to ACE2 receptor of 2019- $\mathrm{nCoV}$

Binding to ACE2 receptor of 2019- nCoV

Binding to ACE2 receptor of 2019- $\mathrm{nCoV}$

Binding to ACE2 receptor of 2019- $\mathrm{nCoV}$

Binding to ACE2 receptor of 2019- $\mathrm{nCoV}$

Binding to ACE2 receptor of 2019- $\mathrm{nCoV}$

Binding to ACE2 receptor of 2019- $\mathrm{nCoV}$

Binding to ACE2 receptor of 2019- $\mathrm{nCoV}$

Binding to ACE2 receptor of 2019- nCoV

Binding to ACE2 receptor of 2019- nCoV

Binding to ACE2 receptor of 2019- $\mathrm{nCoV}$

Binding to ACE2 receptor of 2019- nCoV
$0.33 \pm 0.03$

$1.01 \pm 0.07$

$1.01 \pm 0.07$

0.01

$-7.1$

$-7.1$

$-6.8$

$-6.8$
Peterson, 2020

Kim et al., 2019

Kim et al., 2019

Kim et al., 2019

Cheng J. et al., 2020

Cheng J. et al., 2020

Cheng J. et al., 2020

Cheng J. et al., 2020

Cheng J. et al., 2020

Cheng J. et al., 2020

Cheng J. et al., 2020

Cheng J. et al., 2020

Cheng J. et al., 2020

Cheng J. et al., 2020

Cheng J. et al., 2020

Cheng J. et al., 2020

Cheng J. et al., 2020

Cheng J. et al., 
2020

Polydatin IV

Binding to ACE2 receptor of 2019- $\mathrm{nCoV}$

$-6.4$

$-6.4$

Piceatannol 3,4'-di- $\beta$-D- Binding to ACE2 receptor of 2019- nCoV

glucopyranoside

Puqietinone

Binding to ACE2 receptor of 2019- $\mathrm{nCoV}$

Indigodole B

Blocking the PLP 2 activity of HCoV NL63

Blocking the PLP 2 activity of HCoV NL63

Binding to ACE2 receptor of 2019-nCoV

Binding to ACE2 receptor of 2019-nCoV

Hesperetin

Scutellarin

Binding to ACE2 receptor 2019-nCoV

Curcumin

Desmethylcurcumin

(DMC)

BDMC

(Bisdesmethylcurcumin)

Tangeretin

Hesperetin

Hesperidin

Nobiletin
Binding to Protease Domain (6LU7), Spike

Glycoprotein, and RBD-ACE2 (6LXT)

(6VW1) of SARS-CoV-2

Binding to Protease Domain (6LU7), Spike

Glycoprotein, and RBD-ACE2 (6LXT)

(6VW1) of SARS-CoV-2

Binding to Protease Domain (6LU7), Spike

Glycoprotein, and RBD-ACE2 (6LXT)

(6VW1) of SARS-CoV-2

Binding to Protease Domain (6LU7), Spike

Glycoprotein, and RBD-ACE2 (6LXT)

(6VW1) of SARS-CoV-2

Binding to Protease Domain (6LU7), Spike

Glycoprotein, and RBD-ACE2 (6LXT)

(6VW1) of SARS-CoV-2

Binding to Protease Domain (6LU7), Spike

Glycoprotein, and RBD-ACE2 (6LXT)

(6VW1) of SARS-CoV-2

Binding to Protease Domain (6LU7), Spike

Glycoprotein, and RBD-ACE2 (6LXT)
$2.09 \pm 0.89$

$0.06 \pm 0.04$

$-8.3$

$-14.9$

6LU7

$-11.82$

Spik

$\begin{array}{ll}-8.39 & -9.04\end{array}$

$-11.2$

$-11.51$

$-8.64$

$-7.48$

Utomo et al., 2020

$-8.18$

$-6.51$

Utomo et al., 2020

$-9.08$

$-6.71$

Utomo et al., 2020

$-13$.

$-9$

$-9.50$

Utomo et al., 2020

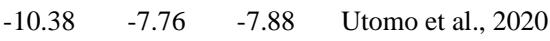


(6VW1) of SARS-CoV-2

Naringenin

Brazilein

Brazilin

Galangin

Aceto Cavicol Acetate

(ACA)

Kaempferol

Quercetin

Luteolin-7- glucoside

Demetoxycurcumine

Naringenin

Apigenine-7- glucoside

Oleuropein

Catechin

Curcumin

Epicatechin-gallate
Binding to Protease Domain (6LU7), Spike

Glycoprotein, and RBD-ACE2 (6LXT)

(6VW1) of SARS-CoV-2

Binding to Protease Domain (6LU7), Spike

Glycoprotein, and RBD-ACE2 (6LXT)

(6VW1) of SARS-CoV-2

Binding to Protease Domain (6LU7), Spike

Glycoprotein, and RBD-ACE2 (6LXT)

(6VW1) of SARS-CoV-2

Binding to Protease Domain (6LU7), Spike

Glycoprotein, and RBD-ACE2 (6LXT)

(6VW1) of SARS-CoV-2

Binding to Protease Domain (6LU7), Spike

Glycoprotein, and RBD-ACE2 (6LXT)

(6VW1) of SARS-CoV-2

Binding to the 3CLpro-6LU7 SARS-CoV-2

Binding to the 3CLpro-6LU7 SARS-CoV-2

Binding to the 3CLpro-6LU7 SARS-CoV-2

Binding to the 3CLpro-6LU7 SARS-CoV-2

Binding to the $3 \mathrm{CL}_{\text {pro- }} 6 \mathrm{LU} 7 \mathrm{SARS}-\mathrm{CoV}-2$

Binding to the 3CLpro-6LU7 SARS-CoV-2

Binding to the 3CLpro-6LU7 SARS-CoV-2

Binding to the $3 \mathrm{CL}_{\text {pro-}} 6 \mathrm{LU} 7 \mathrm{SARS}-\mathrm{CoV}-2$

Binding to the $3 \mathrm{CL}_{\text {pro- }} 6 \mathrm{LU} 7 \mathrm{SARS}-\mathrm{CoV}-2$

Binding to the $3 \mathrm{CL}_{\text {pro- }} 6 \mathrm{LU} 7 \mathrm{SARS}-\mathrm{CoV}-2$

$-12.44$

$-7.40$

$-7.69$

Utomo et al., 2020

$-7.56$

$-7.43$

Utomo et al., 2020

$-7.50$

$-7.49$

Utomo et al., 2020

$-12.96$

$-7.89$

$-7.60$

Utomo et al., 2020

$-9.94$

$-6.05$

$-6.16$

Utomo et al., 2020

$-8.58$

$-8.47$

$-8.17$

$-7.99$

$-7.89$

$-7.83$

$-7.31$

$-7.24$

$-7.05$

$-6.67$
Khaerunnisa et al., 2020

Khaerunnisa et al., 2020

Khaerunnisa et al., 2020

Khaerunnisa et al., 2020

Khaerunnisa et al., 2020

Khaerunnisa et al., 2020

Khaerunnisa et al., 2020

Khaerunnisa et al., 2020

Khaerunnisa et al., 2020

Khaerunnisa et al., 
Zingerol

Gingerol

Allicin

Scutellarein

Myricetin

Myricetin

Methyl rosmarinate,

Calceolarioside B

Licoleafol

Amaranthin

Myricetin 3-O-beta-D-

glucopyranoside

(2S)-Eriodictyol 7-O-(6"-

O-galloyl)-beta-D-

glucopyranoside

$3,5,7,3^{\prime}, 4^{\prime}, 5^{\prime}$-hexahydroxy

flavanone-3-O-beta-D-

glucopyranoside

Nelfinavir- blank

Prulifloxacin- blank

Colistin- blank
Binding to the $3 \mathrm{CL}_{\mathrm{pro}}-6 \mathrm{LU} 7 \mathrm{SARS}-\mathrm{CoV}-2$

Binding to the 3CLpro-6LU7 SARS-CoV-2

Binding to the 3CLpro-6LU7 SARS-CoV-2

Inhibiting ATPase activity of nsP13 of

\section{SARS-CoV}

Inhibiting ATPase activity of nsP13 of

\section{SARS-CoV}

Binding to the receptor-binding site of

\section{SARS-CoV-2 3CLpro}

Binding to the receptor-binding site of

SARS-CoV-2 3CLpro

Binding to the receptor-binding site of

SARS-CoV-2 3CLpro

Binding to the receptor-binding site of

SARS-CoV-2 3CLpro

Binding to the receptor-binding site of

SARS-CoV-2 3CLpro

Binding to the receptor-binding site of

SARS-CoV-2 3CLpro

Binding to the receptor-binding site of

SARS-CoV-2 3CLpro

Binding to the receptor-binding site of SARS-CoV-2 3CLpro

Binding to the receptor-binding site of SARS-CoV-2 3CLpro

Binding to the receptor-binding site of SARS-CoV-2 3CLpro

Binding to the receptor-binding site of
$-5.40$

$-5.38$

$-4.03$

$0.86 \pm 0.48$

$2.71 \pm 0.19$ ul Qamar et al.,

Khaerunnisa et al.,

2020

Khaerunnisa et al.,

2020

Khaerunnisa et al., 2020

Yu et al., 2012

Yu et al., 2012

ul Qamar et al.,

ul Qamar et al.,

ul Qamar et al.,

ul Qamar et al., 2020

ul Qamar et al., 2020

ul Qamar et al., 2020

ul Qamar et al., 2020

ul Qamar et al., 2020 ul Qamar et al., 2020 ul Qamar et al., 2020 
Aloe-emodin

Chitranone

Chrysophanol

Diterpene

Elliptinone

Emetine

Enoxacin

$+(-)$ Epicatechin

Imatinib

Nelfinavir

Niclosamide

Rhein

Scutellarein 7 rutinoside

Withaferin A

Withanolide D

27-Hydroxy withanolide

24-Methyl cholesta-5,23E-

dien-3beta-ol

17 $\alpha$-Hydroxy withanolide
Binding to Protease Domain (6LU7) of

SARS-CoV-2

Binding to Protease Domain (6LU7) of

SARS-CoV-2

Binding to Protease Domain (6LU7) of

SARS-CoV-2

Binding to Protease Domain (6LU7) of

SARS-CoV-2

Binding to Protease Domain (6LU7) of

SARS-CoV-2

Binding to Protease Domain (6LU7) of

SARS-CoV-2

Binding to Protease Domain (6LU7) of

SARS-CoV-2

Binding to Protease Domain (6LU7) of

SARS-CoV-2

Binding to Protease Domain (6LU7) of

SARS-CoV-2

Binding to Protease Domain (6LU7) of

SARS-CoV-2

Binding to Protease Domain (6LU7) of

SARS-CoV-2

Binding to Protease Domain (6LU7) of

SARS-CoV-2

Binding to Protease Domain (6LU7) of

SARS-CoV-2

Binding to Protease Domain (6LU7) of

SARS-CoV-2

Binding to Protease Domain (6LU7) of

SARS-CoV-2

Binding to Protease Domain (6LU7) of

SARS-CoV-2

Binding to Protease Domain (6LU7) of

SARS-CoV-2

Binding to Protease Domain (6LU7) of
Chandel et al., 2020

Chandel et al., 2020

Chandel et al., 2020

Chandel et al., 2020

Chandel et al., 2020

Chandel et al., 2020

Chandel et al., 2020

Chandel et al., 2020

Chandel et al., 2020

Chandel et al., 2020

Chandel et al., 2020

Chandel et al., 2020

Chandel et al., 2020

Chandel et al., 2020

Chandel et al., 2020

Chandel et al., 2020

Chandel et al., 2020

Chandel et al., 
SARS-CoV-2

Aswagandhanoide

Kaempferol

glycoside

(Juglanin)

Nelfinavir- blank

Lopinavir-blank

Ritonavir-blank

Kaempfrol

Hinkonin

Lutein

Bavachinin

Scopadulcic acid

Baicalein

Sylibnin

Solanidine

Narengenin

Oleanane

Dammarenolic

Quercetin
Binding to Protease Domain (6LU7) of

SARS-CoV-2

Inhibiting the 3a protein of SARS-CoV

activity

Binding to Protease Domain (6LU7) of

SARS-CoV-2

Binding to Protease Domain (6LU7) of

SARS-CoV-2

Binding to Protease Domain (6LU7) of

SARS-CoV-2

Binding to Protease Domain (6LU7) of

SARS-CoV-2

Binding to Protease Domain (6LU7) of

SARS-CoV-2

Binding to Protease Domain (6LU7) of

SARS-CoV-2

Binding to Protease Domain (6LU7) of

SARS-CoV-2

Binding to $6 s v b$ of $\mathrm{S}$ protein of SARS-

\section{$\mathrm{CoV}-2$}

Binding to $6 \mathrm{svb}$ of $\mathrm{S}$ protein of SARS-CoV-

2

Binding to $6 \mathrm{svb}$ of $\mathrm{S}$ protein of SARS-CoV-

2

Binding to $6 \mathrm{svb}$ of $\mathrm{S}$ protein of SARS-CoV-

2

Binding to $6 \mathrm{svb}$ of $\mathrm{S}$ protein of SARS-CoV-

Binding to $6 \mathrm{svb}$ of S protein of SARS-CoV-

Binding to Protease Domain (6LU7) of

SARS-CoV-2

Binding to Protease Domain (6LU7) of
2020

$-8.1$

Chandel et al.,

2020

Schwarz et al.,

2014

$-7.92 \pm 0.057$

Ranjan et al., 2020

$-7.52 \pm 0.022$

Ranjan et al., 2020

$-7.42 \pm 0.68$

Ranjan et al., 2020

$-7.68 \pm 0.021$

Ranjan et al., 2020

$-7.51 \pm 0.021$

Ranjan et al., 2020

$-7.58 \pm 0.112$

Ranjan et al., 2020

$-7.74 \pm 0.152$

Ranjan et al., 2020

$-9.6$

Ubani et al., 2020

$-9.4$

Ubani et al., 2020

$-9.2$

Ubani et al., 2020

$-9.1$

Ubani et al., 2020

$-9.0$

Ubani et al., 2020

$-9$

Ubani et al., 2020

$-7.2$

Ubani et al., 2020

$-7.1$

Ubani et al., 2020

SARS-CoV-2 
Solanidine

Silybinin

Loliolide

Shikonin

Herbacetin

Rhoifolin

Pectolinarin

Allyl disulfide

Diallyl tetrasulfide

Allyl

(E)-1-propenyl

disulfide

Allyl methyl trisulfide

Diallyl tetrasulfide

1,2-dithiole

Allyl (Z)-1-propenyl

disulfide

2-vinyl-4H-1,3-dithiine

3-vinyl-1,2-

dithiacyclohex-4-ene

Carvone

Trisulfide, 2-propenyl

propyl

Methyl allyl disulfide
Binding to Protease Domain (6LU7) of

SARS-CoV-2

Binding to Protease Domain (6LU7) of

SARS-CoV-2

Binding to Protease Domain (6LU7) of

SARS-CoV-2

Binding to Protease Domain (6LU7) of

SARS-CoV-2

Binding to the $3 \mathrm{CL}_{\mathrm{pro}}$ of SARS-CoV

Binding to the 3CLpro of SARS-CoV

Binding to the $3 \mathrm{CL}_{\mathrm{pro}}$ of SARS-CoV

Interaction with the ACE2 receptor of

SARS- CoV-2

Interaction with the ACE2 receptor of

SARS- CoV-2

Interaction with the ACE2 receptor of

SARS- CoV-2

Interaction with the ACE2 receptor of

SARS- CoV-2

Interaction with the ACE2 receptor of

SARS- CoV-2

Interaction with the ACE2 receptor of

SARS- $\mathrm{CoV}-2$

Interaction with the ACE2 receptor of

SARS- CoV-2

Interaction with the ACE2 receptor of

SARS- CoV-2

Interaction with the $\mathrm{ACE} 2$ receptor of

SARS- CoV-2

Interaction with the ACE2 receptor of

SARS- CoV-2

Interaction with the ACE2 receptor of

SARS- CoV-2

Interaction with the ACE2 receptor of

SARS- CoV-2 
Diacetonalcohol

Trisulfide, (1E)-1-

propenyl 2- propenyl

Allyl sulfide

1-propenyl methyl

disulfide

Trisulfide, (1Z)-1-

propenyl 2- propenyl

Jensenone

Ecalyptol

Nicotianamine

L. nobilis

T. orientalis

J. oxycredrus ssp.

oxycedrus

C. sempervirens ssp.

pyramidalis

P. palaestina

S. officinalis

S. thymbra

Acyclovir

Glycyrrhizin

Allyl disulfide

Allyl trisulfide

Allyl (E)-1-propenyl

disulfide

allyl methyl trisulfide

Diallyl tetrasulfide

1,2-dithiole

Allyl (Z)-1-propenyl

disulfide

2-vinyl-4H-1,3-dithiine

3-vinyl-1,2-dithiacyclohex-

4-ene

carvone

Trisulfide, 2-propenyl propyl
Interaction with the ACE2 receptor of

$-13.26$

Lin et al., 2017

\section{SARS- CoV-2}

Interaction with the ACE2 receptor of

SARS- CoV-2

Interaction with the ACE2 receptor of

SARS- CoV-2

Interaction with the ACE2 receptor of

SARS- CoV-2

Interaction with the ACE2 receptor of

SARS- CoV-2

Making complex with COVID-19 Mpro

Interaction with COVID-19 Mpro

Inhibiting ACE2 receptor of 2019-nCoV

Interaction with ACE2 receptor of SARS-

$$
\mathrm{CoV}
$$

Interaction with ACE2 receptor of SARS$\mathrm{CoV}$

Interaction with ACE2 receptor of SARS$\mathrm{CoV}$

Interaction with ACE2 receptor of SARS$\mathrm{CoV}$

Interaction with ACE2 receptor of SARS$\mathrm{CoV}$

Interaction with ACE2 receptor of SARS$\mathrm{CoV}$

Interaction with ACE2 receptor of SARS$\mathrm{CoV}$

Interaction with ACE2 receptor of SARS$\mathrm{CoV}$

Interaction with ACE2 receptor of SARS$\mathrm{CoV}$

Interaction with ACE2 receptor of SARS$\mathrm{CoV}-2$

Interaction with ACE2 receptor of SARS$\mathrm{CoV}-2$

Interaction with ACE2 receptor of SARS$\mathrm{CoV}-2$

Interaction with ACE2 receptor of SARS$\mathrm{CoV}-2$

Interaction with ACE2 receptor of SARS$\mathrm{CoV}-2$

Interaction with ACE2 receptor of SARS$\mathrm{CoV}-2$

Interaction with ACE2 receptor of SARS$\mathrm{CoV}-2$

Interaction with ACE2 receptor of SARS$\mathrm{CoV}-2$

Interaction with ACE2 receptor of SARS$\mathrm{CoV}-2$

Interaction with ACE2 receptor of SARS$\mathrm{CoV}-2$

Interaction with ACE2 receptor of SARS$\mathrm{CoV}-2$
$-12.00$

Lin et al., 2017

$-14.24$

Lin et al., 2017

$-13.84$

Lin et al., 2017

$-11.68$

Lin et al., 2017

$-4.8,-5.0,-5.5,-5.5$

Sharma and Kaur,

2020

$-3.9,-4.0,-4.1,-4.2$

Sharma, 2020

$-5.1$

Chen and Du.

2020

$120 \pm 1.2$

Loizzo et al., 2008

$130 \pm 0.4$

$270 \pm 1.5$

$700 \pm 2.3$

$>1000$

$870 \pm 1.5$

641.0

Loizzo et al., 2008

Loizzo et al., 2008

Loizzo et al., 2008

Loizzo et al., 2008

Loizzo et al., 2008

Loizzo et al., 2008

Loizzo et al., 2008

Loizzo et al., 2008

$-12.84$

$-12.76$

$-9.07$

$-12.50$

$-14.06$

$-7.89$

$-9.04$

$-11.83$

$-10.57$

$-8.58$

$-14.01$
Thuy et al., 2020

Thuy et al., 2020

Thuy et al., 2020

Thuy et al., 2020

Thuy et al., 2020

Thuy et al., 2020

Thuy et al., 2020

Thuy et al., 2020

Thuy et al., 2020

Thuy et al., 2020

Thuy et al., 2020 
Methyl allyl disulfide

Diacetonalcohol

Trisulfide, (1E)-1-propenyl

2-propenyl

Allyl sulfide
Interaction with ACE2 receptor of SARS$\mathrm{CoV}-2$ Interaction with ACE2 receptor of SARS$\mathrm{CoV}-2$ Interaction with ACE2 receptor of SARS$\mathrm{CoV}-2$ Interaction with ACE2 receptor of SARS$\mathrm{CoV}-2$
$-10.32$

$-9.71$

$-9.57$

$-9.38$
Thuy et al., 2020

Thuy et al., 2020

Thuy et al., 2020

Thuy et al., 2020

Table 2. Inhibition percentage of plant metabolites on coronaviruses

\begin{tabular}{|c|c|c|c|c|}
\hline \multirow{2}{*}{$\begin{array}{l}\text { Compound } \\
\text { Scutellarein }\end{array}$} & \multirow{2}{*}{$\begin{array}{l}\text { Concentration } \\
10 \mu \mathrm{M}\end{array}$} & \multicolumn{2}{|c|}{ Inhibition percentage (\%) } & \multirow{2}{*}{$\begin{array}{l}\text { Reference } \\
\text { Yu et al., } 2012\end{array}$} \\
\hline & & $100 \%$ & & \\
\hline Myricetin & $10 \mu \mathrm{M}$ & $100 \%$ & & Yu et al., 2012 \\
\hline \multirow[t]{2}{*}{ Psoralen } & $200 \mu \mathrm{M}$ & 3CLpro & PLpro & Park et al., 2015 \\
\hline & & 45 & 40 & \\
\hline Bergapten & $200 \mu \mathrm{M}$ & 40 & 30 & Park et al., 2015 \\
\hline Xanthotoxin & $200 \mu \mathrm{M}$ & 10 & 30 & Park et al., 2015 \\
\hline Isopimpinellin & $200 \mu \mathrm{M}$ & 40 & 80 & Park et al., 2015 \\
\hline 18-hydroxyferruginol & $200 \mu \mathrm{M}$ & $45.8 \pm 5.0$ & & Ryu et al., 2010 \\
\hline Hinokiol & $200 \mu \mathrm{M}$ & $39.1 \pm 11.6$ & & Ryu et al., 2010 \\
\hline Ferruginol & $200 \mu \mathrm{M}$ & $92.7 \pm 3.7$ & & Ryu et al., 2010 \\
\hline 18-oxofer- ruginol & $200 \mu \mathrm{M}$ & $70.5 \pm 1.3$ & & Ryu et al., 2010 \\
\hline O-acetyl-18-hydroxyferruginol & $200 \mu \mathrm{M}$ & $78.6 \pm 8.8$ & & Ryu et al., 2010 \\
\hline Methyl dehydroabi- etate & $200 \mu \mathrm{M}$ & $46.7 \pm 7.2$ & & Ryu et al., 2010 \\
\hline Isopimaric acid & $200 \mu \mathrm{M}$ & $28.9 \pm 2.2$ & & Ryu et al., 2010 \\
\hline Kayadiol & $200 \mu \mathrm{M}$ & $75.2 \pm 5.4$ & & Ryu et al., 2010 \\
\hline Apigenin & $200 \mu \mathrm{M}$ & $280.8 \pm 21.4$ & & Ryu et al., 2010 \\
\hline Luteolin & $200 \mu \mathrm{M}$ & $20.0 \pm 2.2$ & & Ryu et al., 2010 \\
\hline Quercetin & $200 \mu \mathrm{M}$ & $23.8 \pm 1.9$ & & Ryu et al., 2010 \\
\hline Emodin & $200 \mu \mathrm{M}$ & 50 & & Ho et al., 2006 \\
\hline Promazine & $200 \mu \mathrm{M}$ & 55 & & Ho et al., 2006 \\
\hline Rhein & $200 \mu \mathrm{M}$ & $<20$ & & Ho et al., 2006 \\
\hline Chrysin & $200 \mu \mathrm{M}$ & $<20$ & & Ho et al., 2006 \\
\hline Aloeemodin & $100 \mu \mathrm{M}$ & 65 & & Lin et al., 2005 \\
\hline
\end{tabular}




\begin{tabular}{|c|c|c|c|}
\hline Hesperetin & $100 \mu \mathrm{M}$ & 82 or 83 & Lin et al., 2005 \\
\hline Diadzein & $100 \mu \mathrm{M}$ & 72 or 73 & Lin et al., 2005 \\
\hline Baicalein & $10 \mu \mathrm{M}$ & $100 \%$ & Keum et al., 2013 \\
\hline Quercetin-3- $\beta$-galactoside & $50 \mu \mathrm{M}$ & 41.8 & Chen et al., 2006 \\
\hline AMPLS & $200 \mu \mathrm{M}$ & 34 & Nguyen et al., 2012 \\
\hline EGCG & $200 \mu \mathrm{M}$ & 85 & Nguyen et al., 2012 \\
\hline GCG & $200 \mu \mathrm{M}$ & 91 & Nguyen et al., 2012 \\
\hline Diadzein & $200 \mu \mathrm{M}$ & 34 & Nguyen et al., 2012 \\
\hline Puerarin & $200 \mu \mathrm{M}$ & 33 & Nguyen et al., 2012 \\
\hline Quercetin & $200 \mu \mathrm{M}$ & 82 & Nguyen et al., 2012 \\
\hline EGC & $200 \mu \mathrm{M}$ & 5.4 & Nguyen et al., 2012 \\
\hline
\end{tabular}

\section{Conclusion}

Plant metabolites can be potential compounds against the activity of coronaviruses. They possess their antiviral activity through binding to main proteases or amino acid residues in the specific protein receptors of the virus in host cell. Looking through the IC50 values, emetine which is an alkaloid was the most effective compound against the Middle East respiratory synrome (MERS$\mathrm{CoV})$ and it inhibits the virus replication with IC50 value of $0.01 \mu \mathrm{M}$ and Xanthoangelol E had the best activity against papain like protease (PLpro) of severe acute respiratory syndrome (SARS-CoV) with IC50 value of $1.2 \pm 0.4 \mu \mathrm{M}$. Moreover, other polyphenolic compound, tannic acid, was the most effective compound to inhibit the 3CLpro of SARS-CoV with IC50 value of 3 $\mu \mathrm{M}$. In addition, tryptantrin had IC50 value of 0.06 and could bind to the ACE2 receptor of human coronavirus (HCoV NL63). Additionally, baicalein could bind to the ATPase domain of nsP13 (coronavirus helicase) of SARS-CoV with IC50 value of $0.47 \pm 0.09$. On the other hand molecular docking results showed that curcumin, hesperidin, diosmin, apiin, and rutin are 
promising compounds inhibiting COVID-19 protease. Generally studies showed that plant metabolites can be considered as potential anti-coronavirus compounds. 


\section{References}

1. Adem, S., Eyupoglu, V., Sarfraz, I., Rasul, A. and Ali, M., 2020. Identification of potent COVID-19 main protease (Mpro) inhibitors from natural polyphenols: An in silico strategy unveils a hope against CORONA. https://doi.org/10.20944/preprints202003.0333.v1.

2. Balzarini, J., 2007. Carbohydrate-binding agents: a potential future cornerstone for the chemotherapy of enveloped viruses?. Antiviral Chemistry and Chemotherapy, 18(1), pp.1-11. https:// doi.org/ 10.1177/095632020701800101.

3. Barnard, D. L., and Kumaki, Y., 2011. Recent developments in anti-severe acute respiratory syndrome coronavirus chemotherapy. Future Virology, 6(5), 615-631. https:// doi.org/ 10.2217/fvl.11.33.

4. Beck, M.A., 1997. Increased virulence of coxsackievirus B3 in mice due to vitamin E or selenium deficiency. The Journal of nutrition, 127(5), pp.966S-970S. https://doi.org/ 10.1093/jn/127.5.966S.

5. Bleasel, M.D. and Peterson, G.M., 2020. Emetine, Ipecac, Ipecac Alkaloids and Analogues as Potential Antiviral Agents for Coronaviruses. Pharmaceuticals, 13(3), p.51. https://doi.org/10.3390/ph13030051.

6. Calder, P.C., Carr, A.C., Gombart, A.F. and Eggersdorfer, M., 2020. Optimal nutritional status for a well-functioning immune system is an important factor to protect against viral infections. https://doi.org/10.3390/nu12041181.

7. Carr, R.M., Oranu, A. and Khungar, V., 2016. Nonalcoholic fatty liver disease: pathophysiology and management. Gastroenterology Clinics, 45(4), pp.639-652. https://doi.org/10.1016/j.gtc.2016.07.003.

8. Chandel, V., Raj, S., Rathi, B. and Kumar, D., 2020. In Silico Identification of Potent COVID-19 Main Protease Inhibitors from FDA Approved Antiviral Compounds and Active Phytochemicals through Molecular Docking: A Drug Repurposing Approach. https://doi.org/10.20944/preprints202003.0349.v1.

9. Chang, F.R., Yen, C.T., Ei-Shazly, M., Lin, W.H., Yen, M.H., Lin, K.H. and Wu, Y.C., 2012. Anti-human coronavirus (anti-HCoV) triterpenoids from the leaves of Euphorbia neriifolia. Natural product communications, 7(11), p.1934578X1200701103. 
https://doi.org/10.1177/1934578X1200701103.

10. Chen, Y.W., Yiu, C.P.B. and Wong, K.Y., 2020. Prediction of the SARS-CoV-2 (2019$\mathrm{nCoV}$ ) 3C-like protease (3CLpro) structure: virtual screening reveals velpatasvir, ledipasvir, and other drug repurposing candidates. F1000Research, 9. https://doi.org/10.12688/f1000research.22457.2.

11. Chen, Y.C., Shen, S.C., Lee, W.R., Hsu, F.L., Lin, H.Y., Ko, C.H. and Tseng, S.W., 2002. Emodin induces apoptosis in human promyeloleukemic HL-60 cells accompanied by activation of caspase 3 cascade but independent of reactive oxygen species production. Biochemical pharmacology,64(12), pp.1713-1724. https://doi.org/ 10.1016/s0006-2952(02)01386-2.

12. Chen, L., Li, J., Luo, C., Liu, H., Xu, W., Chen, G., Liew, O.W., Zhu, W., Puah, C.M., Shen, X. and Jiang, H., 2006. Binding interaction of quercetin-3- $\beta$-galactoside and its synthetic derivatives with SARS-CoV 3CLpro: Structure-activity relationship studies reveal salient pharmacophore features. Bioorganic and medicinal chemistry, 14(24), pp.8295-8306. https://doi.org/10.1016/j.bmc.2006.09.014.

13. Chen, C., Zuckerman, D.M., Brantley, S., Sharpe, M., Childress, K., Hoiczyk, E. and Pendleton, A.R., 2014. Sambucus nigra extracts inhibit infectious bronchitis virus at an early point during replication. BMC veterinary research, 10(1), p.24. https://doi.org/10.1186/1746-6148-10-24.

14. Chen, H. and Du, Q., 2020. Potential natural compounds for preventing 2019-nCoV infection. Preprints,pp.2020010358-v3. https://doi.org/10.20944/preprints202001.0358.v3

15. Chen, C.N., Lin, C.P., Huang, K.K., Chen, W.C., Hsieh, H.P., Liang, P.H. and Hsu, J.T.A., 2005. Inhibition of SARS-CoV 3C-like protease activity by theaflavin-3, 3'digallate (TF3). Evidence-Based Complementary and Alternative Medicine, 2(2), pp.209215. https://doi.org/ 10.1093/ecam/neh081.

16. Cheng, P.W., Ng, L.T., Chiang, L.C. and Lin, C.C., 2006. Antiviral effects of saikosaponins on human coronavirus $229 \mathrm{E}$ in vitro. Clinical and Experimental Pharmacology and Physiology, 33(7), pp.612-616. https://doi.org/10.1111/j.14401681.2006.04415.x.

17. Cheng, L., Zheng, W., Li, M., Huang, J., Bao, S., Xu, Q. and Ma, Z., 2020. Citrus fruits are rich in flavonoids for immunoregulation and potential targeting ACE2. https://doi.org/ 
10.20944/preprints202004.0152.v1.

18. Cheng, J., Tang, Y., Bao, B. and Zhang, P., 2020. Exploring the Active Compounds of Traditional Mongolian Medicine Agsirga in Intervention of Novel Coronavirus (2019nCoV) Based on HPLC-Q-Exactive-MS/MS and Molecular Docking Method. https://doi.org/10.26434/chemrxiv.11955273.v2.

19. Chiow, K.H., Phoon, M.C., Putti, T., Tan, B.K. and Chow, V.T., 2016. Evaluation of antiviral activities of Houttuynia cordata Thunb. extract, quercetin, quercetrin and cinanserin on murine coronavirus and dengue virus infection. Asian Pacific journal of tropical medicine, 9(1), pp.1-7. https://doi.org/10.1016/j.apjtm.2015.12.002.

20. Cinatl, J., Morgenstern, B., Bauer, G., Chandra, P., Rabenau, H. and Doerr, H.W., 2003. Glycyrrhizin, an active component of liquorice roots, and replication of SARS-associated coronavirus. The Lancet, 361(9374), pp.2045-2046. https://doi.org/10.1016/S01406736(03)13615-X.

21. Clark, K.J., Grant, P.G., Sarr, A.B., Belakere, J.R., Swaggerty, C.L., Phillips, T.D. and Woode, G.N., 1998. An in vitro study of theaflavins extracted from black tea to neutralize bovine rotavirus and bovine coronavirus infections. Veterinary microbiology, 63(2-4), pp.147-157. https://doi.org/ 10.1016/S0378-1135(98)00242-9.

22. Conti, P., Ronconi, G., Caraffa, A., Gallenga, C.E., Ross, R., Frydas, I. and Kritas, S.K., 2020. Induction of pro-inflammatory cytokines (IL-1 and IL-6) and lung inflammation by Coronavirus-19 (COVI-19 or SARS-CoV-2): anti-inflammatory strategies. Journal of biological regulators and homeostatic agents, 34(2). https://doi.org/ 10.23812/CONTI-E.

23. Cos, P., Vlietinck, A. J., Berghe, D. Vanden, and Maes, L., 2006. Anti-infective potential of natural products: How to develop a stronger in vitro "proof-of-concept." Journal of Ethnopharmacology, 106(3), 290-302. https://doi.org/10.1016/j.jep.2006.04.003.

24. D’agostino, M., Tesse, N., Frippiat, J.P., Machouart, M. and Debourgogne, A., 2019. Essential Oils and Their Natural Active Compounds Presenting Antifungal Properties. Molecules, 24(20), p.3713. https://doi.org/ 10.3390/molecules24203713.

25. Damme, E. J. M. Van, Peumans, W. J., Barre, A., and Rougé, P., 1998. Plant Lectins: A Composite of Several Distinct Families of Structurally and Evolutionary Related Proteins with Diverse Biological Roles. Critical Reviews in Plant Sciences, 17(6), 575-692. https://doi.org/ 10.1080/07352689891304276. 
26. De Clercq, E., 2006. Potential antivirals and antiviral strategies against SARS coronavirus infections. Expert review of anti-infective therapy, 4(2), pp.291-302. https://doi.org/ 10.1586/14787210.4.2.291.

27. Dudley, J. P., Golovkina, T. V., and Ross, S. R., 2016. Lessons learned from mouse mammary tumor virus in animal models. ILAR Journal, 57(1), 12-23. https://doi.org/10.1093/ilar/ilv044.

28. Elliott, M.E., Binkley, N.C., Carnes, M., Zimmerman, D.R., Petersen, K., Knapp, K., Behlke, J.M., Ahmann, N. and Kieser, M.A., 2003. Fracture risks for women in long-term care: high prevalence of calcaneal osteoporosis and hypovitaminosis D. Pharmacotherapy: The Journal of Human Pharmacology and Drug Therapy, 23(6), pp.702-710. https://doi.org/10.1592/phco.23.6.702.32182.

29. Galmés, S., Serra, F., and Palou, A., 2018. Vitamin E metabolic effects and genetic variants: A challenge for precision nutrition in obesity and associated disturbances. Nutrients, 10(12). https://doi.org/ 10.3390/nu10121919.

30. Gasmi, A., Noor, S., Tippairote, T., Dadar, M., Menzel, A. and Bjørklund, G., 2020. Individual risk management strategy and potential therapeutic options for the COVID-19 pandemic. Clinical Immunology, p.108409. https://doi.org/ 10.1016/j.clim.2020.108409.

31. Gralinski, L.E. and Menachery, V.D., 2020. Return of the Coronavirus: 2019nCoV. Viruses, 12(2), p.135. https://doi.org/ 10.3390/v12020135.

32. Goodger, J.Q., Seneratne, S.L., Nicolle, D. and Woodrow, I.E., 2016. Foliar essential oil glands of Eucalyptus subgenus Eucalyptus (Myrtaceae) are a rich source of flavonoids and related non-volatile constituents. PloS one, 11(3). https://doi.org/ 10.1371/journal.pone.0151432.

33. Grant, W. B., Lahore, H., McDonnell, S. L., Baggerly, C. A., French, C. B., Aliano, J. L., and Bhattoa, H. P., 2020. Evidence that Vitamin D Supplementation Could Reduce Risk of Influenza and COVID-19 Infections and Deaths. Nutrients, 12(4), 988. https://doi.org/10.3390/nu12040988.

34. Hann, I.M., 1989. Modern Trends in Human Leukemia VII. Journal of clinical pathology, 42(2), p.221. https://doi.org/10.1309/AJCPTGD94EVRSJCG.

35. Hemilä, H., 2003. Vitamin C and SARS coronavirus. Journal of Antimicrobial Chemotherapy, 52(6), pp.1049-1050. https://doi: 10.1097/01.qco.0000160908.79437.be 
36. Hemilä, H., 2017. Vitamin C and infections. Nutrients, 9(4), p.339. https://doi.org/ 10.3390/nu9040339.

37. Ho, T.Y., Wu, S.L., Chen, J.C., Li, C.C. and Hsiang, C.Y., 2007. Emodin blocks the SARS coronavirus spike protein and angiotensin-converting enzyme 2 interaction. Antiviral research, 74(2), pp.92-101. https://doi.org/ 10.1016/j.antiviral.2006.04.014.

38. Hoever, G., Baltina, L., Michaelis, M., Kondratenko, R., Baltina, L., Tolstikov, G.A., Doerr, H.W. and Cinatl, J., 2005. Antiviral Activity of Glycyrrhizic Acid Derivatives against SARS- Coronavirus. Journal of medicinal chemistry, 48(4), pp.1256-1259. https://doi.org/10.1021/jm0493008.

39. Hofmann, H., Geier, M., Marzi, A., Krumbiegel, M., Peipp, M., Fey, G.H., Gramberg, T., Pohlmann, S., 2004b. Susceptibility to SARS coronavirus S protein-driven infection correlates with expression of angiotensin convert- ing enzyme 2 and infection can be blocked by soluble receptor. Biochem. Biophys. Res. Commun. 319, 1216-1221. https://doi.org/10.1016/j.bbrc.2004.05.114.

40. Hudson, J.B., 2018. Antiviral compounds from plants. CRC press. https://doi.org/10.1007/978-1-60761-061-8_24.

41. Huang, H.C., Chu, S.H., Chao, P.D., 1991. Vasorelaxants from Chinese herbs, emodin and scoparone, possess immunosuppressive properties. Eur. J. Phar- macol. 198, 211213. https://doi.org/ 10.1038/sj.bjp.0704205.

42. Huang, C., Wang, Y., Li, X., Ren, L., Zhao, J., Hu, Y., Cao, B., 2020. Clinical features of patients infected with 2019 novel coronavirus in Wuhan, China. The Lancet, 395(10223), 497-506. https://doi.org/ 10.1016/S0140-6736(20)30183-5.

43. Ip, W.E., Chan, K.H., Law, H.K., Tso, G.H., Kong, E.K., Wong, W.H., To, Y.F., Yung, R.W., Chow, E.Y., Au, K.L. and Chan, E.Y., 2005. Mannose-binding lectin in severe acute respiratory syndrome coronavirus infection. Journal of Infectious Diseases, 191(10), pp.1697-1704. https://doi.org/ 10.1086/429631.

44. Jackwood, M. W., Rosenbloom, R., Petteruti, M., Hilt, D. A., McCall, A. W., and Williams, S. M., 2010. Avian coronavirus infectious bronchitis virus susceptibility to botanical oleoresins and essential oils in vitro and in vivo. Virus Research, 149(1), 8694. https://doi.org/10.1016/j.virusres.2010.01.006. 
45. Jee, J., Hoet, A.E., Azevedo, M.P., Vlasova, A.N., Loerch, S.C., Pickworth, C.L., Hanson, J. and Saif, L.J., 2013. Effects of dietary vitamin A content on antibody responses of feedlot calves inoculated intramuscularly with an inactivated bovine coronavirus vaccine. American journal of veterinary research, 74(10), pp.1353-1362. https://doi.org/10.2460/ajvr.74.10.1353.

46. Jo, S., Kim, S., Shin, D.H. and Kim, M.S., 2020. Inhibition of SARS-CoV 3CL protease by flavonoids. Journal of enzyme inhibition and medicinal chemistry, 35(1), pp.145-151. https://doi.org/ 10.1080/14756366.2019.1690480.

47. Jones, H. D., Yoo, J., Crother, T. R., Kyme, P., Ben-Shlomo, A., Khalafi, R., Shimada, K., 2015. Correction: Nicotinamide exacerbates hypoxemia in ventilator-induced lung injury independent of neutrophil infiltration. PLoS ONE, 10(5), 2-3. https://doi.org/10.1371/journal.pone.0128735

48. Kaul, T.N., Middleton Jr, E. and Ogra, P.L., 1985. Antiviral effect of flavonoids on human viruses. Journal of medical virology, 15(1), pp.71-79. https://doi.org/10.1002/jmv.1890150110.

49. Keum, Y.S., Lee, J.M., Yu, M.S., Chin, Y.W. and Jeong, Y.J., 2013. Inhibition of SARS Coronavirus Helicase by Baicalein. Bulletin of the Korean Chemical Society, 34(11), pp.3187-3188. https://doi.org/10.5012/bkcs.2013.34.11.3187

50. Keil, S. D., Bowen, R., and Marschner, S., 2016. Inactivation of Middle East respiratory syndrome coronavirus (MERS-CoV) in plasma products using a riboflavin-based and ultraviolet light-based photochemical treatment. Transfusion, 56(12), 2948-2952. https://doi.org/10.1111/trf.13860.

51. Keyaerts, E., Vijgen, L., Pannecouque, C., Van Damme, E., Peumans, W., Egberink, H., Van Ranst, M., 2007. Plant lectins are potent inhibitors of coronaviruses by interfering with two targets in the viral replication cycle. Antiviral Research, 75(3), 179-187. https://doi.org/10.1016/j.antiviral. 2007.03.003.

52. Kim, H.Y., Eo, E.Y., Park, H., Kim, Y.C., Park, S., Shin, H.J. and Kim, K., 2010. Medicinal herbal extracts of Sophorae radix, Acanthopanacis cortex, Sanguisorbae radix and Torilis fructus inhibit coronavirus replication in vitro. Antivir Ther, 15(5), pp.697709. https://doi.org/10.3851/IMP1615.

53. Kim, D.E., Min, J.S., Jang, M.S., Lee, J.Y., Shin, Y.S., Park, C.M., Song, J.H., Kim, 
H.R., Kim, S., Jin, Y.H. and Kwon, S., 2019. Natural Bis-Benzylisoquinoline AlkaloidsTetrandrine, Fangchinoline, and Cepharanthine, Inhibit Human Coronavirus OC43 Infection of MRC-5 Human Lung Cells. Biomolecules, 9(11), p.696. https://doi.org/10.3390/ biom9110696.

54. Khan, M.T.H., Ather, A., Thompson, K.D. and Gambari, R., 2005. Extracts and molecules from medicinal plants against herpes simplex viruses. Antiviral research, 67(2), pp.107-119. https://doi.org/10.1016/j.antiviral.2005.05.002.

55. Khaerunnisa, S., Kurniawan, H., Awaluddin, R., Suhartati, S. and Soetjipto, S., 2020. Potential Inhibitor of COVID-19 Main Protease (Mpro) From Several Medicinal Plant Compounds by Molecular Docking Study. Prepr. 0226. v1, pp.1-14. https://doi.org/10.20944/preprints202003.0226.v1.

56. Lagarda-Diaz, I., Guzman-Partida, A. M., and Vazquez-Moreno, L., 2017. Legume lectins: Proteins with diverse applications. International Journal of Molecular Sciences, 18(6), 1-18. https://doi.org/10.3390/ijms18061242.

57. Lau, K.M., Lee, K.M., Koon, C.M., Cheung, C.S.F., Lau, C.P., Ho, H.M., Lee, M.Y.H., Au, S.W.N., Cheng, C.H.K., Bik-San Lau, C. and Tsui, S.K.W., 2008. Immunomodulatory and anti-SARS activities of Houttuynia cordata. Journal of Ethnopharmacology, 118(1), pp.79-85. https://doi.org/10.1016/j.jep.2008.03.018.

58. Lelešius, R., Karpovaite, A., Mickiene, R., Drevinskas, T., Tiso, N., Ragažinskiene, O., Šalomskas, A., 2019. In vitro antiviral activity of fifteen plant extracts against avian infectious bronchitis virus. BMC Veterinary Research, 15(1), 1-10. https://doi.org/10.1186/s12917-019-1925- 6.

59. Li, W., Moore, M.J., Vasilieva, N., Sui, J., Wong, S.K., Berne, M.A., Somasundaran, M., Sullivan, J.L., Luzuriaga, K., Greenough, T.C. and Choe, H., 2003. Angiotensinconverting enzyme 2 is a functional receptor for the SARS coronavirus. Nature, 426(6965), pp.450-454. https://doi.org/10.1038/d41573-020-000160.

60. Li, S.Y., Chen, C., Zhang, H.Q., Guo, H.Y., Wang, H., Wang, L., Zhang, X., Hua, S.N., Yu, J., Xiao, P.G. and Li, R.S., 2005. Identification of natural compounds with antiviral activities against SARS-associated coronavirus. Antiviral research, 67(1), pp.18-23. https://doi.org/10.1016/j.antiviral.2005.02.007. 
61. Li, Y.Q., Li, Z.L., Zhao, W.J., Wen, R.X., Meng, Q.W. and Zeng, Y., 2006. Synthesis of stilbene derivatives with inhibition of SARS coronavirus replication. European journal of medicinal chemistry, 41(9), pp.1084-1089. https://doi.org/10.1016/j.ejmech.2006.03.024.

62. Li, Y., Zhang, J., Wang, N., Li, H., Shi, Y., Guo, G., Liu, K., Zeng, H. and Zou, Q., 2020. Therapeutic Drugs Targeting 2019-nCoV Main Protease by High-Throughput Screening. bioRxiv. https://doi.org/10.1101/2020.01.28.922922.

63. Lin, S.C., Ho, C.T., Chuo, W.H., Li, S., Wang, T.T. and Lin, C.C., 2017. Effective inhibition of MERS-CoV infection by resveratrol. BMC infectious diseases, 17(1), p.144. https://doi.org/10.1186/s12879-017-2253-8.

64. Ludwiczuk, A., Skalicka-Woźniak, K. and Georgiev, M.I., 2017. Terpenoids. In: Pharmacognosy. Elsevier, pp.233-266. https://doi.org/10.1016/B978-0-12-8021040.00011-1.

65. Mazalovska, M., and Kouokam, J. C., 2018. Lectins as promising therapeutics for the prevention and treatment of HIV and other potential coinfections. BioMed Research International, 2018. https://doi.org/10.1155/2018/3750646.

66. Matsumoto, M., MUKAI, T., Furukawa, S. and OHORI, H., 2005. Inhibitory effects of epigallocatechin gallate on the propagation of bovine coronavirus in Madin-Darby bovine kidney cells. Animal Science Journal, 76(5), pp.507-512. https://doi.org/10.1111/j.17400929.2005.00297.x.

67. McGill, J.L., Kelly, S.M., Guerra-Maupome, M., Winkley, E., Henningson, J., Narasimhan, B. and Sacco, R.E., 2019. Vitamin A deficiency impairs the immune response to intranasal vaccination and RSV infection in neonatal calves. Scientific reports, 9(1), pp.1-14. https://doi.org/10.1038/s41598-019-51684-x.

68. Mickymaray, S., 2019. Efficacy and mechanism of traditional medicinal plants and bioactive compounds against clinically important pathogens. Antibiotics, 8(4). 635. https://doi.org/10.3390/antibiotics8040257.

69. Macchiagodena, M., Pagliai, M. and Procacci, P., 2020. Inhibition of the main protease 3cl-pro of the coronavirus disease 19 via structure-based ligand design and molecular modeling. arXiv preprint arXiv:2002.09937. https://doi.org/10.1016/j.cplett.2020.137489.

70. Mohajer Shojai, T., Ghalyanchi Langeroudi, A., Karimi, V., Barin, A., and Sadri, N., 2016. The effect of Allium sativum (Garlic) extract on infectious bronchitis virus in 
specific pathogen free embryonic egg. Avicenna Journal of Phytomedicine, 6(4), 458267. https://doi.org/10.22038/AJP.2016.6455.

71. Min, N., Leong, P.T., Lee, R.C.H., Khuan, J.S.E. and Chu, J.J.H., 2018. A flavonoid compound library screen revealed potent antiviral activity of plant-derived flavonoids on human enterovirus A71 replication. Antiviral research, 150, pp.60-68. https://doi.org/10.1016/j.

72. Mohammadi, N. and Shaghaghi, N., 2020. Inhibitory effect of eight Secondary Metabolites from conventional Medicinal Plants on COVID_19 Virus Protease by Molecular Docking Analysis. https://doi.org/10.26434/chemrxiv.11987475.v1.

73. Moradi, M.T., Karimi, A., Rafieian-Kopaei, M. and Fotouhi, F., 2017. In vitro antiviral effects of Peganum harmala seed extract and its total alkaloids against Influenza virus. Microbial pathogenesis, 110, pp.42-49. https://doi.org/ 10.1016/j.micpath.2017.06.014.

74. Nguyen, T.T.H., Woo, H.J., Kang, H.K., Kim, Y.M., Kim, D.W., Ahn, S.A., Xia, Y. and Kim, D., 2012. Flavonoid-mediated inhibition of SARS coronavirus 3C-like protease expressed in Pichia pastoris. Biotechnology letters, 34(5), pp.831-838. https://doi.org/10.1007/s10529-011-0845-8.

75. O’Keefe, B. R., Giomarelli, B., Barnard, D. L., Shenoy, S. R., Chan, P. K. S., McMahon, J. B., McCray, P. B., 2010. Broad-Spectrum In Vitro Activity and In Vivo Efficacy of the Antiviral Protein Griffithsin against Emerging Viruses of the Family Coronaviridae. Journal of Virology, 84(5), 2511-2521. https://doi.org/0.1128/JVI.02322-09

76. Özçelik, B., Kartal, M. and Orhan, I., 2011. Cytotoxicity, antiviral and antimicrobial activities of alkaloids, flavonoids, and phenolic acids. Pharmaceutical biology, 49(4), pp.396-402.x. https://doi.org/10.3109/13880209.2010.519390.

77. Peng, J., Lin, T., Wang, W., Xin, Z., Zhu, T., Gu, Q. and Li, D., 2013. Antiviral alkaloids produced by the mangrove-derived fungus Cladosporium sp. PJX-41. Journal of natural products, 76(6), pp.1133-1140. https://doi.org/10.1021/np400200k

78. Park, J.Y., Yuk, H.J., Ryu, H.W., Lim, S.H., Kim, K.S., Park, K.H., Ryu, Y.B. and Lee, W.S., 2017. Evaluation of polyphenols from Broussonetia papyrifera as coronavirus protease inhibitors. Journal of enzyme inhibition and medicinal chemistry, 32(1), pp.504512. https://doi.org/10.1080/14756366.2016.1265519 
79. Park, C.S., Ahn, Y., Lee, D., Moon, S.W., Kim, K.H., Yamabe, N., Hwang, G.S., Jang, H.J., Lee, H., Kang, K.S. and Lee, J.W., 2015. Synthesis of apoptotic chalcone analogues in HepG2 human hepatocellular carcinoma cells. Bioorganic and medicinal chemistry letters, 25(24), pp.5705-5707. https://doi.org/10.1016/j.bmcl.2015.10.093.

80. Powers, H.J., 2003. Riboflavin (vitamin B-2) and health. The American journal of clinical nutrition, 77(6), pp.1352-1360. https://doi.org/10.1093/ajcn/77.6.1352.

81. Prajapat, M., Sarma, P., Shekhar, N., Avti, P., Sinha, S., Kaur, H., Kumar, S., Bhattacharyya, A., Kumar, H., Bansal, S. and Medhi, B., 2020. Drug targets for corona virus: A systematic review. Indian journal of pharmacology, 52(1), p.56. https://doi.org/10.4103/ijp.IJP_115_20.

82. Ritchie, G., Harvey, D. J., Feldmann, F., Stroeher, U., Feldmann, H., Royle, L., Rudd, P. M., 2010. Identification of $\mathrm{N}$-linked carbohydrates from severe acute respiratory syndrome (SARS) spike glycoprotein. Virology, 399(2), 257-269. https://doi.org/10.1016/j.virol.2009.12.020.

83. Ranjan, A., Chauhan, A., Gurnani, M. and Jindal, T., 2020. Potential Phytochemicals as Efficient Protease Inhibitors of 2019-nCoV. https://doi.org/10.20944/preprints202004.0240.v1.

84. Ryu, Y.B., Jeong, H.J., Kim, J.H., Kim, Y.M., Park, J.Y., Kim, D., Naguyen, T.T.H., Park, S.J., Chang, J.S., Park, K.H. and Rho, M.C., 2010. Biflavonoids from Torreya nucifera displaying SARS-CoV 3CLpro inhibition. Bioorganic and medicinal chemistry, 18(22), pp.7940-7947. https://doi.org/10.1016/j.bmc.2010.09.035.

85. Song, J.M., Lee, K.H. and Seong, B.L., 2005. Antiviral effect of catechins in green tea on influenza virus. Antiviral research, 68(2), pp.66-74. https://doi.org/10.1016/j.antiviral.

86. Schnitzler, P., Schuhmacher, A., Astani, A., and Reichling, J., 2008. Melissa officinalis oil affects infectivity of enveloped herpesviruses. Phytomedicine, 15(9), 734-740. https://doi.org/10.1016/j.phymed.2008.04.018.

87. Saif, L.J., 2004. Animal coronaviruses: Lessons for SARS. Learning from SARS: Preparing for the Next Disease Outbreak. The National Academies Press, Washington, DC, pp.138-149. https://doi.org/10.17226/10915.

88. Sharma, A.D. and Kaur, I., 2020. Molecular docking studies on Jensenone from eucalyptus essential oil as a potential inhibitor of COVID 19 corona virus 
infection. arXiv preprint arXiv:2004.00217. http://doi.org/10.5281/zenodo.3748477.

89. Sharma, A.D., 2020. Eucalyptol (1, 8 cineole) from Eucalyptus Essential Oil a Potential Inhibitor of COVID 19 Corona Virus Infection by Molecular Docking Studies. https://doi.org/10.20944/preprints202003.0455.v1

90. Singh, R. S., Tiwary, A. K., and Kennedy, J. F., 1999. Lectins: Sources, activities, and applications. Critical Reviews in Biotechnology, 19(2), 145-178. https://doi.org/10.1080/0738-859991229224.

91. Chouhan, S., Sharma, K. and Guleria, S., 2017. Antimicrobial activity of some essential oils_-present status and future perspectives. Medicines, 4(3), p.58. https://doi.org/10.3390/medicines4030058.

92. Sydiskis, R.J., Owen, D.G., Lohr, J.L., Rosler, K.H.A., Blomster, R.N., 1991. Inactivation of enveloped viruses by anthraquinones extracted from plants. Antimicrob. Agents Chemother. 35, 2463-2466. https://doi.org/10.1128/AAC.35.12.2463

93. Schwarz, S., Sauter, D., Wang, K., Zhang, R., Sun, B., Karioti, A., Bilia, A.R., Efferth, T. and Schwarz, W., 2014. Kaempferol derivatives as antiviral drugs against the 3a channel protein of coronavirus. Planta medica, 80(02/03), pp.177-182. https://doi.org/10.1055/s0033-1360277.

94. Song, J.M., Lee, K.H. and Seong, B.L., 2005. Antiviral effect of catechins in green tea on influenza virus. Antiviral research, 68(2), pp.66-74. https://doi.org/10.1016/j.

95. Takahashi, S., Yoshiya, T., Yoshizawa-Kumagaye, K. and Sugiyama, T., 2015. Nicotianamine is a novel angiotensin-converting enzyme 2 inhibitor in soybean. Biomedical Research, 36(3),

pp.219-224. Https://doi.org/10.2220/biomedres.36.219.

96. Tapas, A.R., Sakarkar, D.M. and Kakde, R.B., 2008. Flavonoids as nutraceuticals: a review. Tropical journal of Pharmaceutical research,7(3), pp.1089-1099. Https://doi.org/10.4314/tjpr.v7i3.14693.

97. Tsai, Y.C., Lee, C.L., Yen, H.R., Chang, Y.S., Lin, Y.P., Huang, S.H. and Lin, C.W., 2020. Antiviral Action of Tryptanthrin Isolated from Strobilanthes cusia Leaf against Human Coronavirus N N63. Biomolecules, 10(3), p.366. Https://doi.org/10.3390/biom10030366.

98. Tadera, K., Minami, Y., Takamatsu, K. and Matsuoka, T., 2006. Inhibition of $\alpha-$ 
glucosidase and $\alpha$-amylase by flavonoids. Journal of nutritional science and vitaminology, 52(2), pp.149-153. Https://doi.org/10.3177/jnsv.52.149.

99. Thuy, B.T.P., My, T.T.A., Hai, N.T.T., Hieu, L.T., Hoa, T.T., Thi Phuong Loan, H., Triet, N.T., Anh, T.T.V., Quy, P.T., Tat, P.V. and Hue, N.V., 2020. Investigation into SARS-CoV-2 Resistance of Compounds in Garlic Essential Oil. ACS Omega. https://doi.org/10.1021/acsomega.0c00772.

100. Utomo, R.Y. and Meiyanto, E., 2020. Revealing the Potency of Citrus and Galangal Constituents to Halt SARS-CoV-2 Infection. Https://doi.org/10.1080/14756366.2019.1690480

101. ul Qamar, M.T., Alqahtani, S.M., Alamri, M.A. and Chen, L.L., 2020. Structural basis of SARS-CoV-2 3CLpro and anti-COVID-19 drug discovery from medicinal plants. Journal of pharmaceutical analysis. Https://doi.org/10.1016/j.jpha.2020.03.009.

102. Ubani, A., Agwom, F., Shehu, N.Y., Luka, P., Umera, E.A., Umar, U., Omale, S., Nnadi, E. and Aguiyi, J.C., 2020. Molecular Docking Analysis Of Some Phytochemicals On Two SARS-CoV-2 Targets. bioRxiv. Https://doi.org/10.1101/2020.03.31.017657.

103. Ulasli, M., Gurses, S.A., Bayraktar, R., Yumrutas, O., Oztuzcu, S., Igci, M., Igci, Y.Z., Cakmak, E.A. and Arslan, A., 2014. The effects of Nigella sativa (Ns), Anthemis hyalina (Ah) and Citrus sinensis (Cs) extracts on the replication of coronavirus and the expression of TRP genes family. Molecular biology reports, 41(3), pp.1703-1711. https://doi.org/10.1007/s11033-014-3019-7.

104. Van der Meer, F. J. U. M., de Haan, C. A. M., Schuurman, N. M. P., Haijema, B. J., Peumans, W. J., Van Damme, E. J. M., Egberink, H. F., 2007. Antiviral activity of carbohydrate-binding agents against Nidovirales in cell culture. Antiviral Research, 76(1), 21-29. https://doi.org/10.1016/j.antiviral.2007.04.003.

105. Vasconcelos, I. M., and Oliveira, J. T. A., 2004. Antinutritional properties of plant lectins. Toxicon, 44(4), 385-403. https://doi.org/10.1016/j.toxicon.2004.05.005.

106. Villamor, E., Mbise, R., Spiegelman, D., Hertzmark, E., Fataki, M., Peterson, K.E., Ndossi, G. and Fawzi, W.W., 2002. Vitamin A supplements ameliorate the adverse effect of HIV-1, malaria, and diarrheal infections on child growth. Pediatrics, 109(1), pp.e6-e6. https://doi.org/10.1542/peds.109.1.e6.

107. Wen, C.C., Kuo, Y.H., Jan, J.T., Liang, P.H., Wang, S.Y., Liu, H.G., Lee, C.K., 
Chang, S.T., Kuo, C.J., Lee, S.S. and Hou, C.C., 2007. Specific plant terpenoids and lignoids possess potent antiviral activities against severe acute respiratory syndrome coronavirus. Journal of medicinal chemistry, 50(17), pp.4087-4095. https://doi.org/10.1021/jm070295s.

108. Wang, L., Ma, Q., 2018. Clinical benefits and pharmacology of scutellarin: A comprehensive review. Pharmacol Ther 190, 105-127. https://doi.org/10.1016.

109. Wang, W., Ma, X., Han, J., Zhou, M., Ren, H., Pan, Q., Zheng, C. and Zheng, Q., 2016. Neuroprotective effect of scutellarin on ischemic cerebral injury by downregulating the expression of angiotensin-converting enzyme and AT1 receptor. PloS one, 11(1). https://doi.org/10.1371/journal.pone.0146197.

110. Xu, Z., Peng, C., Shi, Y., Zhu, Z., Mu, K., Wang, X. and Zhu, W., 2020. Nelfinavir was predicted to be a potential inhibitor of 2019-nCov main protease by an integrative approach combining homology modelling, molecular docking and binding free energy calculation. BioRxiv. https://doi.org/10.1101/2020.01.27.921627 .

111. Yi, L., Li, Z., Yuan, K., Qu, X., Chen, J., Wang, G., Zhang, H., Luo, H., Zhu, L., Jiang, P. and Chen, L., 2004. Small molecules blocking the entry of severe acute respiratory syndrome coronavirus into host cells. Journal of virology, 78(20), pp.1133411339. https://doi.org/10.1128/JVI.78.20.11334-11339.

112. Yin, J., Li, G., Li, J., Yang, Q. and Ren, X., 2011. In vitro and in vivo effects of Houttuynia cordata on infectious bronchitis virus. Avian pathology, 40(5), pp.491-498. https://doi.org/10.1080/03079457.2011.605107.

113. Yu, M.S., Lee, J., Lee, J.M., Kim, Y., Chin, Y.W., Jee, J.G., Keum, Y.S. and Jeong, Y.J., 2012. Identification of myricetin and scutellarein as novel chemical inhibitors of the SARS coronavirus helicase, nsP13. Bioorganic and medicinal chemistry letters, 22(12), pp.4049-4054. https://doi.org/10.1016/j.bmcl.2012.04.081.

114. Zaki, A. M., Van Boheemen, S., Bestebroer, T. M., Osterhaus, A. D. M. E., and Fouchier, R. A. M., 2012. Isolation of a novel coronavirus from a man with pneumonia in Saudi Arabia. New England Journal of Medicine, 367(19), 1814-1820. https://doi.org/10.1056/NEJMoa1211721.

115. Zhang, P., Liu, X., Liu, H., Wang, W., Liu, X., Li, X. and Wu, X., 2018. Astragalus polysaccharides inhibit avian infectious bronchitis virus infection by 
regulating viral replication. Microbial pathogenesis, 114, pp.124-128. https://doi.org/10.1016/j.micpath.2017.11.026.

116. Zhang, L., and Liu, Y., 2020. Potential interventions for novel coronavirus in China: A systematic review. Journal of Medical Virology, 92(5), 479-490. https://doi.org/10.1002/jmv.25707. 
High lights

- Plants metabolites can be potential drugs to inhibit various types of coronaviruses.

- $\quad$ IC50 value and molecular docking score and binding energy are parameters to inhibit the coronaviruses

- $\quad$ This is the first comprehenisve study on all secondary plant metabolites such as polyphenols (flavonoids, coumarins, stilbenes), alkaloids, terpenoids, organosulfur compounds saponins, saikosaponins, lectins, essential oils, nico and primary metabolites such as vitamins. 